University of San Diego

Digital USD

2015-12

\title{
Exploring Unintended Pregnancy in the United States Military: A Phenomenological Approach
}

Mary Kathryn Phillips

University of San Diego

Follow this and additional works at: https://digital.sandiego.edu/dissertations

Part of the Nursing Commons

\section{Digital USD Citation}

Phillips, Mary Kathryn, "Exploring Unintended Pregnancy in the United States Military: A Phenomenological Approach" (2015). Dissertations. 28.

https://digital.sandiego.edu/dissertations/28

This Dissertation: Open Access is brought to you for free and open access by the Theses and Dissertations at Digital USD. It has been accepted for inclusion in Dissertations by an authorized administrator of Digital USD. For more information, please contact digital@sandiego.edu. 


\title{
UNIVERSITY OF SAN DIEGO
}

Hahn School of Nursing and Health Science

DOCTOR OF PHILOSOPHY IN NURSING

EXPLORING UNINTENDED PREGNANCY IN THE UNITED STATES MILITARY:

A PHENOMENOLOGICAL APPROACH

by

Mary Kathryn Phillips

A dissertation presented to the

FACULTY OF THE HAHN SCHOOL OF NURSING AND HEALTH SCIENCE UNIVERSITY OF SAN DIEGO

\author{
In partial fulfillment of the \\ requirements for the degree \\ DOCTOR OF PHILOSOPHY IN NURSING
}

$12 / 16 / 2015$

Dissertation Committee

Jane Georges, $\mathrm{PhD}$, RN, Chairperson

Joseph Burkard, DNSc, CRNA

Kathy James, DNSc, FNP, FAAN 


\begin{abstract}
Nearly half of the 6.7 million pregnancies in the United States each year are unintended. The U.S. unintended pregnancy rate is significantly higher than the rate in many other developed countries. By age 45, more than half of all American women will have experienced an unintended pregnancy, and three in ten will have had an abortion. Previous empirical research has aimed to fix the rate of unintended pregnancy before it was adequately explored. The rationale for this study emanated from the belief that interventions intended to reduce the rate of unintended pregnancy will be more successful if the essence of unintended pregnancy is better understood. The purpose of this phenomenological study was to generate skepticism about accepted meanings and interpretations concerning unintended pregnancy and to critique ideologies that distort those meanings and interpretations. The rate of unintended pregnancy for women in the U.S. military, using the most conservative measure, is $50 \%$ higher than rates of unintended pregnancy among similarly aged women in the general, non military, public. Using a critical hermeneutic philosophical approach, this study used the lived experience, as described by servicewomen who faced an unintended pregnancy, as a tool for better understanding the social, cultural, political, and historical context in which that pregnancy occurred. Findings suggest that women at risk for unintended pregnancy may not have the practical knowledge to critically think about their own sexual practices, may have a poor appreciation of their sexual selves, and may fear moral judgment for acknowledging any sexual behaviors.
\end{abstract}


(Intentionally Blank) 
Dedication

For Theresa. 
Preface 


\section{Table of Contents}

$\begin{array}{ll}\text { Abstract } & \text { iii }\end{array}$

Dedication $\quad$ V

Table of Contents $\quad$ vi

List of Tables vii

1. Introduction 1

$\begin{array}{ll}\text { A. Significance } & 4\end{array}$

B. Purpose and Research Questions 5

C. Lines of Inquiry 6

D. Research Design 6

$\begin{array}{ll}\text { E. Assumptions } & 7\end{array}$

F. Key Terminology $\quad 8$

2. Literature Review 11

$\begin{array}{ll}\text { A. Conceptualizations of Unintended Pregnancy } & 13\end{array}$

$\begin{array}{ll}\text { a. Unintended pregnancy as a public burden } & 13\end{array}$

b. Unintended pregnancy as a public health statistic 16

$\begin{array}{ll}\text { c. Unintended pregnancy as a public expense } & 20\end{array}$

B. Avoiding Unintended Pregnancy 24

a. Contraceptive use helps women avoid unintended pregnancy 24

b. Sex education helps women avoid unintended pregnancy 29

c. Motivation helps women avoid unintended pregnancy 34

C. The Concept of Intention 35

$\begin{array}{ll}\text { D. Summary } & 40\end{array}$

3. Methodology 43 
A. Critical Hermeneutics 44

B. Participants 46

$\begin{array}{ll}\text { a. Recruitment } & 46\end{array}$

$\begin{array}{lr}\text { C. Protection of Human Subjects } & 47\end{array}$

D. Data Collection Procedures and Data Analysis 48

E. Data Analysis 48

F. Measures to Assure Credibility 49

4. Findings $\quad 50$

$\begin{array}{lr}\text { A. Participants } & 50\end{array}$

B. Primary and Secondary Themes 51

a. Practical knowledge 51

b. Sexual daughters 56

$\begin{array}{ll}\text { c. Judgment } & 59\end{array}$

$\begin{array}{ll}\text { C. Chapter Summary } & 65\end{array}$

$\begin{array}{ll}\text { 5. Discussion } & 67\end{array}$

$\begin{array}{ll}\text { A. Previous Research } & 67\end{array}$

$\begin{array}{ll}\text { B. Credibility } & 70\end{array}$

$\begin{array}{ll}\text { C. Practical Knowledge Deficiency } & 70\end{array}$

a. Structures of significance allow people to communicate with each other 72

b. Structures of domination related to the transformative capability of action 77

c. Structures of legitimation refers to the normative aspects of actions $\quad 80$

$\begin{array}{ll}\text { D. Implications } & 81\end{array}$

$\begin{array}{ll}\text { a. Practice } & 81\end{array}$

$\begin{array}{ll}\text { b. Education } & 82\end{array}$ 
E. Study Limitations

Appendices

A. Recruitment Flyer $\quad 86$

B. Demographic Research $\quad 87$

C. University of San Diego Institutional Review Board Consent Form 88

D. Initial Research Questions 90

$\begin{array}{ll}\text { References } & 91\end{array}$ 


\section{List of Tables}

Table

Page

1. Categorical division of the selected resources 12

2. Anscombe's category of intention and proposed example of each 36

3. Philosophical underpinnings influencing methodology for inquiry 43

4. Study participants 51

5. Summary of the history of military women and their pregnancies 76 


\section{Chapter 1}

\section{Introduction}

Nearly half of the 6.7 million pregnancies in the United States each year are unintended (Mosher, Jones, \& Abma, 2012). The U.S. unintended pregnancy rate is significantly higher than the rate in many other developed countries (Singh, Sedgh, \& Hussain, 2010). Most women spend at least three decades of their lives trying to avoid pregnancy. By age 45, more than half of all American women will have experienced an unintended pregnancy, and three in ten will have had an abortion (Jones \& Kavanaugh, 2011).

A total of 1.7 million births result from the 3.1 million unintended pregnancies in the United States each year. Sixty-four percent of those births are publicly funded (Sonfield, Kost, Gold, \& Finer, 2011). The annual cost to taxpayers for unintended pregnancy is estimated at $\$ 11.1$ billion to $\$ 12.6$ billion (Frost, Finer, \& Tapales, 2008; Monea \& Thomas, 2011; Sonfield et al., 2011) and accounts for half of the total public expenditure on birth. These estimates do not include long-term costs but are limited to prenatal care, pregnancy, labor and delivery, and infant care for one year. All states share the burden of unintended pregnancies. At least $38 \%$ of pregnancies in every U.S. state are unintended, rising to more than half, in 29 states (Finer \& Kost, 2011).

The rate of all unintended pregnancies among U.S. women aged 15-44 years in the years 2006 to 2010 was 54 per 1,000 pregnancies. Higher rates of unintended pregnancies occur among poor and low-income women (137 per 1,000 pregnancies), Black women (92 per 1,000 pregnancies), women without a high school diploma (80 per 1,000 pregnancies), women aged 20-24 (104 per 1,000 pregnancies), sexually active 
women aged 15-17 (147 per 1,000 pregnancies) and women in the United States military (117 per 1,000 pregnancies) (Finer \& Zolna, 2011; Lindberg, 2011; Mosher, Jones \& Abma, 2012).

Unintended pregnancies contribute significantly to U.S. Department of Defense (DOD) health care spending. In 2011, more than $13 \%$ of total bed days and $5 \%$ of total lost work days among service members were pregnancy and delivery-related. Pregnancyand delivery-related conditions accounted for $57.8 \%$ of all hospitalizations for active duty females in all services. In the Navy, Air Force, and Coast Guard, pregnancy and delivery account for more hospitalizations than any other category of illness or injury for males and females (Defense Medical Surveillance System, 2012).

Total Department of Defense (DOD) healthcare expenditures have more than doubled from $\$ 19$ billion in 2009 to a requested $\$ 48.7$ billion for 2013 (Overview, 2012). The burden of unintended military pregnancies not only affects DOD health care spending but delays training and unit readiness, ultimately affecting armed operations. Unintended pregnancy among military women adversely affects the individual, the military mission, and the allocation of resources.

Contraceptives help women prevent pregnancies they do not want. One hundred years ago, distribution of contraceptives or information about contraception was illegal in the United States (Comstock, n.d.). The subject was considered lewd and obscene. Women were limited to practicing the rhythm method, withdrawal, and prolonged breastfeeding, or illegally procuring diaphragms, condoms, and spermicides. The return of servicemen from World War I with high numbers of venereal diseases transformed the moral issue of sexual intercourse and contraception into a public health issue that 
warranted scientific research, academic discussion (Medicine and Public Health, 18901930), and the legal distribution of contraceptives. Modern contraceptives are extremely effective in preventing pregnancy. Women at risk for unintended pregnancy that use contraceptives consistently and correctly account for only $5 \%$ of unintended pregnancies (Guttmacher Institute, 2013a). Under the Affordable Care Act, FDA-approved contraceptive methods must be provided by private health plans without out-of-pocket costs to consumers (Guttmacher Institute, 2013b). Publicly funded family planning services help women avoid pregnancies. Poor women and women under 20 years of age qualify for these services (Guttmacher Institute, 2013b). Active duty military members receive military health care services with no out-of-pocket costs for contraceptives or contraceptive counseling.

In the United States, $52 \%$ of the 3.1 million women who experience an unintended pregnancy were not using any form of contraception (Guttmacher Institute, 2013a) during the month of conception. In the U. S. military, this figure rises to $62 \%$ of servicewomen presenting with an unintended pregnancy (Custer, Waller, Vernon, \& O'Rourke, 2008). Why do active duty service women, who do not desire a pregnancy, fail to use contraceptives?

Public health goals related to pregnancy intention are projected for the number of intended versus unintended pregnancies. A reproductive health goal for "Healthy People $2020 "$ is to increase the proportion of pregnancies that are intended to $56 \%$ (Office of Population Affairs, 2010). The Navy and Marine Corps Public Health Center Sexual Health and Responsibility Program (SHARP) adopted the same goal (Navy and Marine Corps Public Health Center Sexual Health and Responsibility Program, 2012). SHARP's 
objective is to increase the proportion of intended pregnancies among its youngest, poorest, and least educated members from $36 \%$ to $56 \%$. Stakeholders such as the Centers for Disease Control and Prevention (CDC), the Guttmacher Institute, the Sexuality Information and Education Council of the United States (SIECUS), the Planned Parenthood Federation, and many other public and private organizations commit dollars and time to research that may result in decreased federal and state spending on unintended pregnancies (Sonfield et al., 2011).

\section{Significance}

The high rates of unintended pregnancies in the United States beg for qualitative research to determine why women at risk for negative societal consequences of pregnancy-the poor, the young, and active duty women-, take the greatest chance regarding contraception. Most research to date focuses empirically on access to contraceptive methods, cost, failure rates, and provider preferences. Research has quantitatively measured attitudes and behaviors related to contraception with surveys and multiple-choice methodology (Biggs \& Foster, 2012; Biggs, Karasek, \& Foster, 2012; Foster, Higgins, Karasek, Ma, \& Grossman, 2011). These studies reveal that underestimating the risk of pregnancy is the most common reason for not using contraception leading to unintended pregnancy (Nettleman, Chung, Brewer, Ayoola, \& Reed, 2007; Kay, Suellentrop, \& Sloup, 2009) and that barriers to health care access continue to be a major reason for unprotected intercourse (Biggs et al., 2012). These studies have not explained why women underestimate the risk of pregnancy or why women who want to avoid pregnancy and have free access to contraceptives do not use them. If pregnancy is a conscious decision (Santelli et al., 2003), and contraception is free 
and readily available (military health care), and pregnancy will create financial hardship, negatively impact a career, and change one's life trajectory, why are unintended pregnancies occurring at such a high rate?

The rationale for this study emanates from the belief that interventions intended to reduce the rate of unintended pregnancy, will be more successful if the essence of unintended pregnancy is better understood. Critical truths about the reality of unintended pregnancy are grounded in the lived experience. Antidotes evolving from empirical research are ineffective when the phenomenon, unintended pregnancy, is poorly defined or conceptualized. Nurses are agents of educational, political, and social change. United States' servicewomen are more educated than the general population, are typically 18 years of age or older, are not among the very poor, are not primarily Black or Hispanic, and have free access to contraception and contraceptive counseling (Department of Defense Demographics, 2010). Yet, their unintended pregnancy rate is half again, and sometimes twice, as high as the general population's. Insight into the world of intention for these women may unveil a social process that contributes to understanding the experience of unintended pregnancy.

\section{Purpose and Research Questions}

The rate of unintended pregnancy for women in the U.S. military, using the most conservative measure, is $50 \%$ higher than rates of unintended pregnancy among similarly aged women in the general, non military, public. As many as $62 \%$ of active duty servicewomen, experiencing an unintended pregnancy, were not using contraceptives when they conceived. The overall purpose of this phenomenological study is to generate skepticism about accepted meanings and interpretations concerning unintended 
pregnancy and to critique ideologies that distort those meanings and interpretations. The generative question informing this study is: "Why do servicewomen get pregnant when they don't want to be pregnant?"

\section{Lines of Inquiry}

The following questions will be presented during a dialogue with each participant. Redirection, clarification, or pursuit of a developing concept may produce other questions not identified here.

1. How does the participant define unintended pregnancy?

2. Can the participant describe the setting at the time of the pregnancy?

3. To what extent was the participant motivated to avoid pregnancy?

4. To what extent does the participant perceive the father to have been motivated to avoid pregnancy?

5. Can the participant describe her feelings about the pregnancy?

6. What personal/professional/social changes did participants anticipate experiencing or experience as a result of the pregnancy?

7. Can the participant describe any situation where she may have been asked whether or not the pregnancy was intended?

7. What factors does the participant perceive impeded her ability to avoid pregnancy?

\section{Research Design}

A critical hermeneutic approach, situated in a postmodern feminist perspective will be used for this study. Following approval by the University of San Diego's Institutional Review Board, women with a history of military service who experienced an unintended pregnancy while on active duty will be engaged in dialogue. In-depth 
dialogue will be the primary method of data collection. All conversations will be audio recorded and transcribed verbatim.

Using a critical hermeneutic philosophical approach, the data that are recorded, observed, experienced and transcribed through the dialogue process will be reviewed for similarities and differences. Analysis of those similarities and differences will produce categories or concepts. As more data is collected and more categories are identified, their similarities and differences will be compared to the previously developed concepts. Continued analysis of developing concepts will suggest plausible relationships. The relationship between these evolving concepts will be explored and evaluated for developing themes. As characterized by hermeneutic philosophy, those themes will be interpreted and used to deconstruct unintended pregnancy. The result will be an analysis presented in language intended to transform society and emancipate individuals from distorted communication or false ideology about unintended pregnancy.

\section{Assumptions}

Based on the researcher's background and experience as an active duty servicewoman and Certified Nurse Midwife, four primary assumptions are made regarding this study. These assumptions emerge from a postmodern feminist perspective, which informs this study. First, gender matters. There is a fundamental inequality that exists in the U.S. military regarding men, women, and pregnancy. Second, many individuals have grown up without a consciousness of feminist history. Past struggles and inequities are unknown or unappreciated. Third, a woman's perspective is her reality. Objectivity is amalgamated realities. A woman's reality or a woman's truth is not a result of cause and effect that can be measured empirically, and the knowledge acquired from 
rational application of social scientific theories, or reason, is not necessarily the truth (Harding, 1995; Longino, 1993; Scott, 1991). Finally, the dominant culture, which feminists have identified as essentially patriarchal, has the power to determine what is humanly excellent, worthy of praise, or moral. Pregnancy is a negative consequence of sexual intercourse in contexts deemed unacceptable in the traditional patriarchal model. The phrase, unintended pregnancy, needs to be deconstructed. It has been accepted in an uncriticized fashion and it upholds existing unequal gender power relations.

\section{Key Terminology}

The following definitions of terms will be used for purposes of this study: 1. Active duty. Active duty status means full-time duty in the active military service of the United States. Military refers to any or all of the armed forces. The member has made an oath of enlistment or accepted a commission as an officer with one of the armed forces (Active Duty: The Uniformed Code of Military Justice, n.d.).

2. Intention and acting intentionally: Much academic discussion and study has occurred concerning the use of the concepts of intention and acting intentionally (Adams \& Steadman, 2004a; Adams \& Steadman, 2004b; Knobe, 2004; Hagger \& Chatzisarantis, 2006; Leslie, Knobe \& Cohen, 2006). One view of the core concept of intentional action is that an agent acts intentionally only if the agent intends to do the action (Adams \& Steadman, 2004a). Semantically, it does not matter how the action is observed, it is an intentional act if the agent intends to do the action.

Pragmatically, saying that an action is done intentionally or on purpose implies a judgment of moral responsibility or blame, even if blame is not part of the literal semantic content. The theory of symbolic interactionism, among other things, suggests 
that people behave based on what they believe and not based on what is objectively true (Blumer, 1969). An inquirer can understand a human's action only by understanding the setting, the person's definition of the situation, and how the person interpreted the action. Another view is that there are many factors required for an action to be performed intentionally. One factor is a causal relationship between an intention and an intended action (Adams \& Steadman, 2004a).

Usually when cause, intention, and outcome are present and linked together blame or praise can be attributed to the action. But, when there is a deviation in the normal pattern of cause, intention, and outcome, blame or praise is discounted (Pizarro, Uhlmann \& Bloom, 2003). When there is a connection between a behavior and a negatively received outcome, the action may be interpreted as unintended. There is dispute among philosophers and cognitive scientists, but agreement exists that bad acts done intentionally are morally worse than bad acts done unintentionally (Adams \& Steadman, 2004a). In a patriarchal framework, where morality is defined by justification, saying that something was not done on purpose may be a way to avoid social blame. Whether an action is considered intentional or not influences moral judgment (Leslie, Knobe, \& Cohen, 2006).

Feminist research argues that a woman's epistemic privilege, or her ability to be heard, has resulted in limited knowledge (Hesse-Biber, 2014). The positivist approach of cataloging a pregnancy as intended or unintended stagnates the body of knowledge with interventional designs aimed at fixing something hardly understood. Carol Gilligan (1982/1993) explains that young girls develop a moral sensibility that is based on individualism and caring not necessarily social justice. Yet, in a patriarchal society, it is 
the androcentric rationality that is validated when a woman is asked to label her pregnancy as intended or unintended. 


\section{Chapter 2}

\section{Literature Review}

The literature was reviewed for content that contributed to an understanding of the social phenomenon, unintended pregnancy. Because this study will focus on a population at increased risk, women in the military, there was particular attention to published data, reviews, and editorials regarding unintended pregnancy in this population. Because women, particularly women in the military, are structurally oppressed in relation to the dominant group, men, the literature was reviewed for nuances of power struggles, social injustices, and gender as the categorical center of inquiry.

Peer reviewed articles published primarily in the last five years, and mostly within the last ten years were identified with CINAHL, ERIC, PAIS International, and PubMed search engines using the terms "unintended pregnancy," "military pregnancy," and "concept of intention." Contributing classic works were included regardless of published date. Four books enhanced the literature review by providing an historical account of women in the military (Vuic, 2010), an historical account of birth control use in America (Engelman, 2011), an ethnographic study of sex education in America (Kendall, 2013), and a philosophical analysis of intention (Anscombe, 1957). Eleven articles from popular versus scholarly sources were included for social context contribution. Relevant publications made reference to policy, politics, cost, prevention strategies including education, contraceptive use or nonuse, contraceptive failure and discontinuation, and the concept of intention and intentional acts.

A total of 191 publications contributed to the review, 24\% of which concerned the military. Table 1. Depicts a categorical division of the selected resources. 
Table 1.

\begin{tabular}{|l|l|l|}
\hline Type of Publication & $\begin{array}{l}\text { Number } \\
\text { Reviewed }\end{array}$ & $\begin{array}{l}\text { Concerned the } \\
\text { Military }\end{array}$ \\
\hline Book & 4 & 1 \\
\hline Popular Resource & 11 & \\
\hline Concept of Intention & 7 & 0 \\
\hline Literature Review & 4 & 2 \\
\hline Editorial & 41 & 18 \\
\hline Qualitative Research & 17 & 4 \\
\hline Quantitative Research & 59 & 6 \\
\hline $\begin{array}{l}\text { Formal Briefs or } \\
\text { Statistics }\end{array}$ & 48 & 15 \\
\hline \hline & 191 & 46 \\
\hline Total & & \\
\hline
\end{tabular}

Quantitative research dominated the literature followed by formal statistics or briefs and editorials. Only one of the quantitative studies reported data from interventional research. One publication recommended a guideline for nurses to identify patients at high risk for unintended pregnancy (Taylor \& James, 2011) and one validated an assessment tool for identifying that risk (Sales et al., 2009). Other quantitative studies evaluated data from primarily self-reported surveys (Custer et al, 2008; Finer \& Zolna, 2011; Frost, Lindberg, \& Finer, 2012; Grindlay \& Grossman, 2013). The large number of statistical reports and briefs supported a need for new research in order to meet SHARP and "Healthy People 2020" goals for improved intended pregnancy rates (Mosher et al, 2012; Kaye, Suellentrop, \& Sloup, 2009).

Qualitative studies were few and focused primarily on decision making (Bender, 2008; Chung-Park, 2007; Hoggart, 2012; Raine et al., 2010) and contraceptive challenges (Akers, Gold, Borrero, Santucci, \& Schwarz, 2010; Campo, Askelson, Spies, \& Losch, 2010; Dennis \& Grossman, 2012; Duke \& Ames, 2008; Higgins, Hirsch, \& Trussell, 2008). In general, the literature regarded unintended pregnancy as a social and financial 
burden. Few publications addressed why, in a first-world country, in the twenty-first century, nearly half of all pregnancies are conceived without intention. Seven publications that considered the concept of intention were reviewed regardless of date published. They provided philosophical dialogue that may explain how pregnancy becomes a negative, but morally forgivable consequence, when described as unintended.

Publications were reviewed with a focus on gender struggles and inequities, feminist history and perspectives, and pregnancy as a negative social consequence of unprotected intercourse, particularly for women in the military. Through this feminist lens, two themes developed: defining and avoiding unintended pregnancy. Once established, the two themes acted as a guide for further data collection and interpretation. Finally, the current literature as well as the classic work by Gertrude Elizabeth Margaret Anscombe (1957), was reviewed for a better understanding of present and previous philosophical dialogue about the concept of intention.

\section{Conceptualizations of Unintended Pregnancy}

Defining unintended pregnancy was one of two themes that developed during the literature review. The literature repeatedly explains the phenomenon of unintended pregnancy through descriptors that underscore its general negative impact on the society as well as the mother and child.

Unintended pregnancy as a public burden. The ability to plan pregnancies is directly linked to decreased poverty and increased educational and workforce opportunities for women (Tsui, McDonald-Mosley, \& Burke, 2010). Centers for Disease Control and Prevention (CDC) identified family planning as one of the 10 great public health achievements in the United States during the 20th century (CDC, 2013). The 
ability of women to seek more education and equality with men, coincides with the ability to plan pregnancies. Family or pregnancy planning is affirmed as a social positive. Americans strongly support family planning. Seven in ten Americans support the goal of reducing unintended pregnancies (Unplanned Pregnancy as it Relates to Women, Men, Children, and Society, 2009).

The negative consequences associated with pregnancies that are unintended, compared to those that are intended, are many. Women who have unintended pregnancies are 2.5 times more likely to begin prenatal care after the first trimester. After controlling for background characteristics, infants born as a result of an unintended pregnancy are at risk for low birth weight and preterm birth, and are less likely to be breastfed (Unplanned Pregnancy and Family Turmoil, 2008). Children born as a result of an unplanned pregnancy have significantly lower cognitive test scores compared to children born of an intended pregnancy (Unplanned Pregnancy as it Relates to Women, Men, Children, and Society, 2009). One in five unintended pregnancies occurs among adolescents (U.S. Department of Health and Human Services Office of Population Affairs, 2010). Adolescents and their children endure greater negative consequences associated with unintended pregnancy. Teenaged mothers are less likely to graduate from high school or pass a General Education Development (GED) test; they earn less money than those who delay childbearing; and they receive twice as much federal aid for nearly twice as long (Hoffman, 2006).

Adolescent pregnancies are rarely intended. Eighty-two percent of teenaged pregnancies (ages 15-19) are unintended (Finer, 2010; Guttmacher Institute, 2012a). The United States arguably has the highest teen pregnancy rate in the developed world, twice 
that of Canada or Sweden (Guttmacher Institute, 2011). In 2008, 7\% of U.S. adolescents became pregnant. As staggering as that figure is, it represents a $43 \%$ decline from the peak of teen pregnancies in 1990 (Guttmacher Institute, 2012a). Only 14\% of the decline is attributed to decreased sexual activity, $86 \%$ of the decline is attributed to improved contraceptive use (Guttmacher Institute, 2011). Although the majority of electively aborted pregnancies are considered unintended, adolescents aged 15-19 accounted for only 16\% of all abortions in 2008 (Pazol et al., 2011). By their 19th birthday, seven out of ten adolescents are sexually active (Guttmacher Institute, 2012a). According to the Pregnancy Risk Assessment Monitoring System (PRAMS), more than half (50.1\%) of the approximately 400,000 adolescents who gave birth in the United States in 2011, were not using any method of birth control to prevent the pregnancy (CDC, 2012).

American youth can enter the military as young as seventeen. Comparing rates of unintended pregnancies in the military to unintended pregnancies in the general population is made difficult because of the greater number of younger women in the military, as well as the under reporting of abortions. Among the 198,000 active duty female service members of reproductive age, 19,200 to 23,100 unintended pregnancies occur each year (Custer et al., 2008; Grindlay, Yanow, Jelinska, Gomperts, \& Grossman, 2011). The rate is consistently higher for younger, enlisted women than for officers (Holt, Grindlay, Taskier, \& Grossman, 2011; Lindberg, 2011). Almost one-third of first births in the military are to women younger than 21 years of age (Klein \& Adelman, 2008).

From the 1940s, when women first received regular appointments in the U.S. military, to the mid 1970s, pregnancy and motherhood were considered incompatible with military service (Holm, 1992). If a woman intended to remain on active duty, she 
would not plan a pregnancy. Pregnancy was grounds for involuntary dismissal until 1975 (Morden, 1990). Today, military women can plan pregnancies around initial enlistment and training periods, when thousands of dollars are spent per recruit (United States Department of Defense, 2013), and around deployments, during which the military bears tremendous cost to transport and replace a servicewoman due to pregnancy (Ponder \& Nothnagle, 2010). Active duty men are not removed from deployment or derailed from their military career trajectory for fathering a pregnancy, intentionally or unintentionally.

Unintended pregnancy as a public health statistic. Data collection regarding the intention to become pregnant began in the 1940s (Whelpton \& Kiser, 1943); however, the demographic and politically correct research jargon of the past may not reveal the information on pregnancy intention that is needed today. For example, responses to survey questions that infer a relationship with a sexual partner, such as "married," "not married," or "cohabitating" do not necessarily capture data related to pregnancy intention (Finer \& Zolna, 2014; Lindberg \& Singh, 2008; Maxson \& Miranda, 2011).

There are two surveys currently used in the United States to assess pregnancy intention: The National Survey of Family Growth (NSFG) and the Pregnancy Risk Assessment Monitoring System (PRAMS). NSFG and PRAMS use several questions to assess pregnancy intention. International surveys, such as the Demographic and Health Surveys (DHS) and the CDC-assisted Reproductive Health Surveys, generally ask only one question. More than fifteen years ago, Kaufmann, Morris, \& Spitz found a 25\% discordance rate among women answering both NSFG and DHS questions about their most recent pregnancy, suggesting that survey data may not be an accurate reflection of intent to become pregnant (Kauffmann, Morris, \& Spitz, 1997). 
Unintended pregnancies are either unwanted (ocurring when no children, or no more children, are desired) or mistimed (occurring earlier than desired). In contrast, pregnancies are described as intended if they occur at the right time or later than desired (because of infertility or difficulties conceiving). Unplanned pregnancy is a concept related to unintended pregnancy. An unplanned pregnancy is often described as one that occurs when a woman uses contraceptive methods but becomes pregnant anyway or when she does not desire a pregnancy and fails to use contraceptives. The semantic versus conceptual difference between the expressions "unplanned" and "unintended" will be explored later in this chapter. Pregnancies ending in elective abortion are generally considered to have been unintended. All of these descriptions assume that pregnancy is a woman's conscious decision (Santelli et al., 2003). None assumes paternal intention.

Demographic shifts in the U.S. population may affect the accuracy of assessments of pregnancy intention. Demographic characteristics typically examined with respect to unintended pregnancy include income and education levels, age, marital status, and race or ethnicity. The number of women affected by an economic recession, such as the one that began in 2007, affect unintended pregnancy rates (Finer and Zolna, 2014). For instance, poor women have five times the unintended pregnancy rate of the highest income women (Finer \& Zolna, 2014). Improved measure of demographic subgroups, like cohabitating women, affects unintended pregnancy rates regardless of behaviors (e.g., contraceptive use) contraceptive use, within subgroups (Finer \& Zolna, 2014). While the poor and the young continue to have the highest rates of unintended pregnancy, the relative impermanence of both marriage and cohabitation means that a woman may be single at different periods in her life. According to Lindberg and Singh (2008), 
government surveyors and other researchers may be out of touch with the reality of sexual behavior among single women. Nine out of ten single women aged 20-44 are sexually experienced and 70\% are sexually active (Lindberg \& Singh, 2008). Half are at risk of experiencing an unintended pregnancy. Marital status, even cohabitation status, as a risk assessment demographic for unintended pregnancy, may be outdated.

Finer and Kost (2011), in an effort to measure the impact of state policies (e.g., those governing sex education and funding of contraceptive services) on unintended pregnancy, discovered that six states and the District of Columbia had poor survey data. They suggested that looking only at demographic characteristics (such as marital status) as measures of pregnancy intention is inadequate and limited.

Maxson and Miranda (2011) examined the dichotomous classification of pregnancy as intended or unintended. They suggested that although both are "unintended," a mistimed pregnancy could be inherently different from an unwanted pregnancy. They conducted a prospective cohort study of pregnant women in North Carolina and discovered that although women with mistimed and unwanted pregnancies were similar demographically, they were psychosocially different. Depression and negative paternal support scores were higher and positive paternal support scores were lower among women reporting an unwanted pregnancy versus a mistimed pregnancy. Tsui, McDonald-Mosley, and Burke (2010) also questioned the dichotomization of pregnancy intention in health surveys, as well as the retrospective, and potentially biased recall, necessitated by survey questions. They acknowledged that there are limitations in data collection or measurement instruments and raised questions about the current analysis. Finer and Zolna (2014) identified unintended pregnancies as either mistimed or 
unwanted in their methodology for monitoring trends in pregnancy intention.

Trussel, Schwarz, and Guthrie (2010) suggested that developing and validating a measure of pregnancy intention is a research priority. They indicated that such a measure should be prospective to enable clinicians to tailor contraceptive counseling and provide trends for policymakers.

Data from all branches of the military indicate higher unintended pregnancy rates among military women compared to the general U.S. population (Lindberg, 2011). Like the general population, the unintended pregnancy rate is increased in younger women, women with less education, nonwhite women and those in cohabitating unions (Holt, Grindlay, Taskier, \& Grossman, 2011; Lindberg, 2011; Custer et al, 2008). Age is almost always inversely associated with pregnancy intention, as demonstrated by Custer and colleagues in a study designed to assess the variables associated with unintended pregnancy among U.S. Army women (Custer et al, 2008).

The Guttmacher Institute reported that the highest unintended pregnancy rate is usually in women 20-24 years of age (Guttmacher Institute, 2012b). 2010 census data indicated that $9.9 \%$ of the general population was between 18 and 24 years of age. According to Department of Defense demographics, half (50.3\%) of the military's enlisted personnel and $13.4 \%$ of its officers are under 25 years of age (Department of Defense, 2010). Higher percentages of young adults in the military compared to the general population may contribute to higher unintended pregnancy rates (Ponder \& Nothnagle, 2010).

Similarly, approximately $85 \%$ of U.S. adults possess a high school diploma, compared to $93 \%$ of military enlisted personnel. About $20 \%$ of the military personnel are 
officers and nearly $83 \%$ of them have a bachelor's degree or higher. High school dropouts and the college educated have the same rate of intended births, but high school dropouts have more unintended births (Musick, England, Edgington, \& Kangas, 2009). Military members are younger than the general population, but they are generally more highly educated (Department of Defense, 2010). Some socio-demographic differences between the military and the general population (e.g., age) may contribute to higher unintended pregnancy rates and some (e.g., education) do not (Holt et al, 2011).

Unintended pregnancy as a public expense. Monea and Thomas (2011) broke down public costs associated with pregnancy using 2001 data and inflating to 2008 dollars. The average cost of elective pregnancy termination is $\$ 576$. Public costs associated with fetal loss ranges from $\$ 730$ to $\$ 1,522$ per instance. The average cost of a publicly financed birth is $\$ 7,171$. The average cost of a year's worth of infant care is estimated at $\$ 6,100$. In a review of the literature regarding the costs of unintended pregnancies and unintended pregnancy-related complications for third party payers, Huynh and colleagues' (2013) restated the predominate recommendation found in most publications to reduce unintended pregnancies in order to save tax payer dollars.

Taxpayer spending on unintended pregnancies in the United States is described in the literature as an economic burden and, an opportunity for potential and substantial savings if unintended pregnancy rates can be reduced. Data regarding public spending on unintended pregnancy supports public policy campaigns that recommend funding of contraceptives, sex education, and elective abortion (Center on Children and Families at Brookings, 2012; Gold, 2011; Huynh et al., 2013; James \& Rashid, 2013; Sonfield \& Kost, 2013). The Guttmacher Institute suggested that without publicly funded family 
planning efforts, the annual public costs of births from unintended pregnancy would be twice as high as the estimated $\$ 12.5$ billion dollars (Monea \& Thomas, 2011; Sonfield \& Kost, 2013; Sonfield et al, 2011).

Medicaid, the Children's Health Insurance Program (CHIP), and the Indian Health Service (IHS) are the three systems that cover the costs of pregnancy-related care through public funding for poor and low-income women. In 2008, $48 \%$ of all U.S. births were publicly funded. In 2008, 1.7 million births (average estimate from state and national survey data) resulted from unintended pregnancies and $65 \%$ of them were publicly funded. Public funding accounted for only $36 \%$ of intended births that same year (Sonfield \& Kost, 2013).

States vary in the demographic composition of their populations. They also vary in restrictions on abortion, harassment at abortion clinics, sex education policies, and adolescent pregnancy rates. The demographic disparities associated with pregnancy intention are known from the data collected by the NSFG. NSFG has been collecting pregnancy intention data on women ages 15-44 since 1973 (Mosher et al, 2012). This survey, as noted previously, reports the standard measure of unintended pregnancy for the United States, as well as national data on births and abortion incidence. NSFG estimated 1.67 million births resulted from unintended pregnancies in the United States in 2008 (Sonfield \& Kost, 2013).

Finer and Kost (2011) believed that state-level data may be useful in order to compare state specific policies, such as abortion restriction and sex education, that may have an effect on unintended pregnancy rates. PRAMS measure state-level data regarding pregnancy intention. It was not until 2007, that collection of PRAMS data occurred in 
most states. PRAMS and other state-specific surveys reported 1.81 million births from unintended pregnancies in 2008 (Sonfield \& Kost, 2013). Finer and Kost (2011) found that no state had a consistent decline in unintended pregnancy, and 29 states plus the District of Columbia, had an upward trend between 2002 and 2008. In eleven states or jurisdictions, at least $70 \%$ of births resulting from unintended pregnancies were paid for by public programs (Sonfield, Kost, Gold \& Finer, 2011). In Louisiana and Mississippi, $81 \%$ of the births resulting from unintended pregnancies were publicly funded (Sonfield, Kost, Gold \& Finer, 2011). Of the $\$ 11.1$ billion that funded unintended pregnancy birth costs in 2006, $\$ 4.6$ billion were state expenditures. In seven states the costs for funding unintended pregnancies exceed half a billion dollars. In 2006, California and Texas spent about $\$ 1.3$ billion each (Sonfield et al, 2011) in order to fund unintended pregnancies.

Service men and women receive their health care at Military Treatment Facilities (MTF). MTFs are funded by the Department of Defense and are strategically located in and out of the continental United States. The DOD also funds a military health plan, which covers the costs of approved medications and other medical services not available at MTFs. For 2013, the DOD requested $\$ 48.7$ billion (taxpayer) dollars for healthcare expenditures (Overview, 2012).

Because it is imperative for military armed operations and readiness, each active duty member's health record includes an Individual Medical Readiness (IMR) status. The IMR determines whether or not the military member is medically approved for deployment. In addition to the FY2013 defense budget requests, the DOD published long-term performance goals. In FY2008, only $67 \%$ of the U.S. military members met medical approval for deployment. In FY2011, only 78\% met medical approval for 
deployment. For FY2013, the defense budget's long-term performance goals

recommended reducing growth in overall health care costs and suggested that $85 \%$ of the U.S. Armed Forces have an IMR reflecting readiness for deployment in FY2014 (Overview, 2012).

Pregnancy and delivery related conditions rank among the top ten conditions accounting for relatively large proportions of the morbidity and health care burdens that affect U.S. military members. Four mental health disorders and two pregnancy and delivery-related conditions account for more than one half of all hospital bed days for active duty personnel (Defense Medical Surveillance System, 2012). Pregnancy, and the year following the birth of a child, delay military readiness.

Little is known about the frequency, costs, or burdens associated with military women and abortion access because there are few to no studies related to military women and abortion (Holt et al., 2011). Pregnancies that are electively aborted are statistically considered unintended. The Guttmacher Institute estimated that $65 \%$ of active duty military pregnancies are unintended. Since 1979, use of DOD funds for abortions has been prohibited (Boostra, 2007; Burrelli, 2013; Ponder \& Nothnagle, 2010). Exceptions were made for cases where the life of the mother was in danger and for pregnancies resulting from rape or incest. In 1981 the exceptions were restricted.

Efforts to modify the law pertaining to federal funds and abortions have been a part of legislative processes since 1996. Most recently, The National Defense Authorization Act for fiscal year 2013 restricted the use of DOD funds and DOD facilities to perform abortions except where the life of the mother would be endangered if the fetus were carried to term or in a case in which the pregnancy is the result of an act of 
rape or incest (Burrelli, 2013). In other words, the exceptions were reinstated. Policies that limit access and make the costs of reproductive health services prohibitive create undue burdens for women. In March of 2013, the Military Access to Reproductive Care and Health (MARCH) for Military Women bill, which would allow MTFs to conduct elective abortions if female service members used private funds to pay for the service (Kime, 2013) was reintroduced. The bill would give military women nearly the same access to reproductive health care as their civilian sisters.

\section{Avoiding Unintended Pregnancy}

The second theme that developed from the literature review is the desire to "fix" the problem. Unintended pregnancy is avoidable.

Contraceptive use helps women avoid unintended pregnancy. In a first-world country in the twenty-first century, if a woman does not want to conceive, does she practice contraception? Eleven percent of women at risk for unintended pregnancy are not using any contraceptive method (Guttmacher Institute, 2013a). The freedom to use contraceptives was achieved through sacrifices of pioneering women like Margaret Sanger. With the advent of birth control options, American women can separate sex from reproduction and enjoy planned pregnancies that coincide with career, financial, family, and personal health goals.

Unfortunately, despite the availability of safe and effective contraception in the United States, nonuse and inconsistent use are prevalent among women who do not want to become pregnant. More than half of the unintended pregnancies in this country occur among women who were not using contraceptives, and an additional $43 \%$ occur among 
women using a method inconsistently or incorrectly (Guttmacher Institute, August 2013;

Jones, Mosher, Daniel \& Division of Vital Statistics, 2012; Speidel \& Harper, 2008).

The history of women's struggle to obtain access to contraceptives began in the early 1900s and coincided with the introduction to the concept of public health. In the late 1800 s cities and states created boards of health to regulate sources of diseases. There was tension between public health and the practice of private medicine (Medicine and Public Health, 1890-1930, n.d.). Public health officials, nurses, and nurse midwives implemented public health programs, including dispensary medicine. The American Medical Association (AMA) lobbied for control over prescription drugs and medical treatment. With these controls, private medicine could indirectly profit from public health initiatives.

The practice of birth control was common in the United States prior to 1914 (Engelman, 2011). There was a 50\% drop in fertility rate between 1800 and 1900, particularly in urban regions, as a result of contraceptive techniques including rhythm method, withdrawal, diaphragms, condoms, contraceptive sponges, prolonged breastfeeding and spermicides (Engelman, 2011). In the 1870s, a social purity movement developed that viewed contraception as immoral practice promoting prostitution and venereal disease. In 1873, the Comstock Act, a federal law that prohibited mailing of any form of contraceptive information, was passed and subsequent state laws extended the federal law by outlawing the use and distribution of contraceptives (Comstock Act, n.d.). Margaret Sanger, a nurse and social activist, who came of age during the period of the Comstock laws, was outraged that poor and working-class women could not obtain contraception, yet upper-class women who had access to private physicians could 
(Chesler, 1992). Sanger boosted the birth control movement into the forefront of American society through the publication and distribution of literature about contraception, the creation of a birth control clinic that provided free contraceptive services to women, and the promotion of research that lead to the development of the birth control pill (Chesler, 1992).

During the age of purity advocates and Comstock laws, the military did not distribute condoms, nor endorse their use. The U.S. was the only military force in World War I that did not supply condoms to its troops (Engelman, 2011). Despite all of the efforts, arrests, exiles, and risks the female activists endured, it was probably the return of servicemen from World War I and their venereal diseases that turned the tide on public discussion about sexual matters. Public health officials were able to address issues such as the spread of syphilis without much competition from private physicians (Medicine and Public Health, n.d.). In 1919, Congress gave the Public Health Service responsibility for veterans and service-related disabilities (Medicine and Public Health, n.d.). Because a government institution, the Public Health Service, was engaged in public discussion of sexual matters, contraception became an issue of public health for men and women.

In the early 1900s the country's approaches to provide contraception and avoid unintended pregnancies were rooted in interplay of political, cultural and socioeconomic forces. The same is true today. The Affordable Care Act (ACA) requires health care insurance plans to cover preventive services without out-of-pocket expense to the consumer. Those services include provision of all Food and Drug Administration (FDA) approved contraceptive methods, along with sterilization procedures and contraceptive counseling to all women (Guttamacher Institute, 2013a). Some religious organizations 
argue that providing coverage for contraception violates their religious beliefs and have demanded exemption, despite evidence that religiosity, assessed by frequency of attendance at religious services, does not correlate with contraceptive use (Jones \& Dreweke, 2011). No religious groups have opposed medication for erectile dysfunction among unmarried males despite religious tenets that suggest sexual intercourse is to be practiced exclusively in the context of marriage. Women disproportionately bear the consequences of sexual activity in their risk of pregnancy. Exempting religious groups from the requirement to provide contraceptives may systematically discriminate against one group of citizens, women (Gossett, Kiley, \& Hammond, 2013).

Modern contraceptives are extremely effective in preventing pregnancy. Women who use contraceptives consistently and correctly account for only $5 \%$ of all unintended pregnancies (Guttmacher Institute, 2013a). Reference to effective versus highly effective methods of contraception is found throughout the literature (Guttmacher Institute, 2013a; World Health Organization [WHO], 2012). The male condom, considered an effective method of contraception, is $98 \%$ effective with perfect use. Typical use is a better indicator of effectiveness. The failure rate of the male condom is $18 \%$ with typical use. Typical use failure rates are high where the method requires user intervention. The contraceptive implant and intrauterine device (IUD), highly effective methods, are the most effective reversible contraceptive methods available, with failure rates of less than $1 \%$ for both perfect and typical use (Guttmacher Institute, 2013a).

Long-acting and reversible contraception (LARC) is the term used to refer to contraceptive implants and IUDs. First year failure rates are low for LARCs and one-year continuation rates are superior to short-acting reversible contraceptives (WHO, 2012). 
Many providers in current practice have outdated perceptions regarding appropriate candidates for LARC (Speidel \& Harper, 2008). For example, some providers believe that there is a need for parent or partner consent for LARC use and some limit LARC use based on age or parity (WHO, 2012). Providers continue to be concerned about unsubstantiated infection risks of intrauterine contraception and fewer than $65 \%$ generally discuss the option with their patients (Speidel \& Harper, 2008). Perceived contraindications to intrauterine contraceptive methods have been largely disproved (WHO, 2012). Women of any age, despite the number of times they have been pregnant, if any, as well as those who are postpartum or post abortion are eligible for intrauterine contraceptive use (Speidel \& Harper, 2008). There is a public health movement to promote LARC use (Dragoman, Davis, \& Banks, 2010).

Emergency contraception (EC) was thought to decrease the number of unintended pregnancies but has had no measurable benefit in clinical trials (Baecher,Weaver, \& Raymond, 2009). EC is a post coital contraceptive method for the prevention of an unintended pregnancy after unprotected sexual intercourse.

The unintended pregnancy rate for sexually active adolescents aged 15-17 is 147 per 1,000. By their nineteenth birthday, seven in ten adolescent girls have had intercourse (Guttmacher Institute, 2012a). The United States has the highest teen pregnancy and birth rate in the world (CDC, 2012). The male condom is the most commonly used method at first intercourse and at most recent sexual encounter among teenaged men and women (Guttmacher Institute, 2012).

Seventy-five percent of military recruits are under 22 years of age. In a 2008 survey of unmarried active duty sailors and marines, risky sexual behavior that included 
number of sexual partners, frequency of intercourse and failure to use condoms was highest among the 17-20 age group (Bray, et al., 2009). Almost one-third of first births in the military are to women under twenty-one years of age (Klein \& Adelman, 2008). The Navy has reported enlisted personnel unintended pregnancy rates as high as $64 \%$ (SHARP, 2012) and the Army as high as 50\% (Custer et al, 2008). Custer and colleagues (2008) found that age was inversely associated with pregnancy intention and women in the seventeen to twenty year age group were most likely to report an unintended pregnancy. Active duty service personnel have access to contraception methods and other reproductive health services at no cost. Condoms are accessible in numerous venues and as of February 2010, emergency contraception is required to be available at all military treatment facilities (Boonstra, 2010). In spite of contraceptive availability, however, unintended pregnancy among active duty servicewomen is largely related to the lack of contraceptive use (Goyal, Borrero, \& Schwarz, 2011).

Sex education helps women avoid unintended pregnancy. Adolescents have sex. By their nineteenth birthdays, seven in ten adolescents have had intercourse (Guttmacher Institute, 2012a). The WHO reported that combination efforts such as improved access to contraception and sex education help prevent unintended pregnancies (Ramos, 2011).

Sex education is difficult for Americans. Sex education by parents and within structured education systems is still limited by feelings of discomfort and embarrassment. Sex, like other intimate details of life, is still taboo. A strong social dichotomy exists related to the human sexual activity, and the ability to talk about the subject. Innate to human development, sex and its entourage of behaviors and language, captivates society 
through elements that define our culture: music, drama, media, fashion, politics, and social behavior. Yet, there is a collective sense of impropriety associated with sexual discourse in the home between parent and child, in politics regarding the design and delivery of school age curriculum, and in health care between provider and patient.

Parent and child communication about sex is recommended throughout the literature (Guilamo-Ramos \& Bouris, 2009; Beckett et. al., 2010; Commendador, 2010). Parents believe it is important to talk to their children about sex, but most do not do so (Wilson, Dalberth, Koo, \& Gard, 2010). Communication about sex should start early, happen frequently, and be specific. Parents find it easier to talk about sex if they start discussing developmentally appropriate sex-related topics when their children are very young (Wilson et al., 2010). The conversations about sex can be interwoven into daily communication about health, hygiene, family, finances, and so on. Later, when it is time to be more specific, the taboo is diffused.

The content of communication is important. Some parents believe they have talked about sex, but specific information about intercourse, condom use, and sexually transmitted diseases was never presented (Guilamo-Ramos \& Bouris, 2009). Parents need, and don't always feel they have, the knowledge and confidence to communicate effectively with their children (Miller et al., 2009). There are also gender barriers to parent-child communication about sex. Fathers need particular support when communicating with daughters (Wilson \& Koo, 2010).

The United States has the highest teen pregnancy and birth rates, 66 per 1,000 and 29 per 1,000 respectively, in the developed world (CDC, 2012). They exceed rates for countries like Germany, France, the Netherlands, Canada, and the United Kingdom by 
two-, three- and up to sixfold (Stanger-Hall \& Hall, 2011). U.S. adolescents engage in sexual activity at levels similar to their Canadian and Western European peers, but are less likely to use contraception (Guttmacher Institute, 2012a). Countries with adolescent birth rates of three per thousand (the Netherlands) and seven per thousand (France) also have significantly lower abortion rates. Sex education in these countries begins in kindergarten and includes comprehensive information including contraceptive use (Henderson, 2012). The high adolescent pregnancy and birth rates in the United States compared to other countries has been attributed to major debates over sex education curricula in public school. The design and delivery of school age curricula for sex education has been argued since the 1980s. Advocates for either comprehensive sex education (CSE) or abstinence only until marriage education (AOUME) have waged intense political battles at national, state, and school district levels.

Kendall provided insight into the actual practice, myths, and truths of AOUME and CSE in her book, "The Sex Education Debates" (Kendall, 2013). Kendall's work is based on ethnographic research conducted in California, Florida, Wisconsin, and Wyoming and attempted in Maryland between 2004 and 2009.

Between 1996 and 2009, federal funding (excluding matching state funds) for AOUME programs peaked at $\$ 176$ million annually (Trenholm et al., 2011). According to Kendall (2013), AOUME curricula depict teens as gendered and in need of moral transformation for the good of society. AOUME curricula teach that sex outside of marriage, and anything other than heterosexual sex is never viewed as good, and AOUME curricula recognizes diversity as a marketing challenge, not a different way of living. Kendall, (2013) describes both AOUME and CSE curricula as treating the 
students as consumers. CSE provides evidenced-based information so that students can be better consumers and make better health choices. Neither curriculum views teen pregnancy as good, and cultural differences that may challenge the value of teen pregnancy, are not addressed in CSE curricula (Kendall, 2013).

A study by Lindberg and Maddow-Zimet (2012) concluded that sex education about abstinence and birth control was associated with healthier sexual behaviors. Unfortunately, one-third of teens have not received any formal instruction about contraception (Guttmacher Institute, 2012b). Forty-six percent of males and $33 \%$ of females do not receive formal instruction about contraception before they first have intercourse (Guttmacher Institute, 2012b).

An evidenced-based Teen Pregnancy Prevention Initiative (TPPI) was signed into law in December 2009. This was the first federal investment dedicated to preventing adolescent pregnancy through research (Stanger-Hall \& Hall, 2011). TPPI and the Personal Responsibility Education Program (PREP) CSE curricula, have been implemented under the Obama administration. Prior to TPPI, federally funded sex education and pregnancy prevention curricula was not evidenced-based. Between 1997 and 2008, \$1.5 billion federal dollars funded programs that prohibited the discussion of contraceptive methods (Lindbert \& Maddow-Zimet, 2012). Despite evidence that abstinence only programs are ineffective (Santelli, 2006; Trenholm et al., 2007), funding was restored for abstinence only education and authorized by legislature in 2010 (SEICUS, 2010). With federal funding available for both AOUME and CSE programs, states have an opportunity to decide, if they incorporate sex education into their public 
school curricula, which type of sex education, evidenced-based comprehensive education or abstinence-only education, is a better investment for preventing adolescent pregnancy.

Between 2007 and 2010, there was a state level trend to support more comprehensive sex education, but in 2011 more conservative legislation at the state level halted CSE progress (Sonfield, 2012). As of 2012, 37 states required abstinence to be covered and 18 states require AOUME curricula. Eighteen states and the District of Columbia require their sex education curricula to include information on contraception (Sonfield, 2012). Policies, however, cannot accurately predict what individual teachers teach in schools.

While Kendall's (2013) research clearly described how AOUME and CSE programs support and defend efforts to protect youth from the negative consequences of sex, the ethnographic story produced a more valuable message: The focus of educating American youth about sex should be on developing critical thinkers who can recognize themselves and their peers as sexual beings, talk about sex in their homes and public institutions, and address social mores and values with informed discussions.

Political and social constraints that surround sex education in the classroom also influence health care provider efforts to educate patients in health care settings. The literature depicts providers' limited knowledge of contraception as a barrier to sexual health counseling and prevention of pregnancy (Akers et al., 2010; Dehlendorf, Levy, Ruskin, \& Steinauer, 2011; Shields, 2009). A poorly educated health care provider can affect a woman's contraceptive use. Akers and colleagues (2010) found provider limitations that included knowledge, training, and personal discomfort with the topic. System limitations included time with patients and competing health priorities. 
Dehlendorf, Levy, Ruskin, and Steinauer (2011) identified younger providers as more knowledgeable and suggested a lack of consistent and accurate knowledge about contraception among physicians, nurse practitioners and physician assistants.

Regarding the efforts to reduce unintended pregnancies, facilitate access to contraception, or provide nonjudgmental options, a limited number of interventions are identified in the literature. Shields (2009) called for a stronger investment in provider training and continuing education in reproductive health and family planning. Taylor (2011) proposed a public health framework that incorporates standard primary care competencies for pre conceptual counseling and reproductive health.

Motivation helps women avoid unintended pregnancy. Motivation is the impetus needed to overcome ambivalence. Based on systematic review of the literature, ambivalence about getting pregnant was the one personal characteristic repeatedly associated with unintended pregnancy and poor or no contraceptive use (Curtis, Evens, \& Sambisa, 2011; Custer et al., 2008; Higgins, Hirsch, \& Trussell, 2008). Ambivalence prevents action. Avoiding pregnancy requires action. Motivation to have sex has nothing to do with motivation to prevent pregnancy.

Ambivalence is defined as the coexistence of opposing attitudes or feelings (Ambivalence, n.d.). Sigmund Freud's classic work (1913) explored the concept of ambivalence and its association with taboo (Freud, 2010). Freud described taboo as a social creation (Freud, 2010). Society determines when pregnancy is inappropriate, for example during adolescence or a military obligation. The underlying desire for pregnancy may coexist with the understanding of a strong social prohibition toward the pregnancy. The basis of taboo is a prohibited action and a strong inclination to perform that action. 
Intentional violation of a taboo can lead to severe penalties, embarrassment, or shame (Freud, 2010).

Hoggart (2012) examined teenage pregnancy decision making in England. She suggested that decision-making is compromised in the presence of competing value systems, or a desire for pregnancy versus the social taboo that suggests teenage

pregnancy is wrong. Bender (2008) interviewed three Icelandic girls and discovered the process of decision making to be less rational when the decision is difficult and personal. Higgins, Hirsch, and Trussell (2008) correlated sexual pleasure or an intensified charge of the sexual encounter with pregnancy ambivalence. For many participants in their study, the risk of pregnancy heightened the pleasure derived from sexual encounters. Furthermore, their description of an "escapist pleasure in imagining that a pregnancy would sweep one away from all hardship" (Higgins et al., 2008 p. 130) may have future research applicability for active duty servicewomen.

\section{The Concept of Intention}

The United States has been surveying women about pregnancy intention since the 1940s (Whelpton \& Kiser, 1943). The literature does not reveal why surveys ask about unintended pregnancy, why the word unintended was chosen, and whether the meaning of unintended pregnancy was expected to be intuitively obvious. The concept of intention or acting intentionally has been a philosophical and linguistic topic of debate for three quarters of a century (Anscombe, 1957). It is beyond the scope of this proposal to succinctly define what it means to describe an act as unintended. Literature review does, however, reveal defining attributes that are agreeable to most involved in the debates over the concept of intention (Adams \& Steadman, 2004a; Adams \& Steadman, 2004b; 
Knobe, 2004; Knobe, 2006; Leslie, Knobe, \& Cohen, 2006).

"Intention," by Gertrude Elizabeth Margaret Anscombe (Anscombe, 1957), is considered a classic in moral philosophy. Anscombe assesses the concept of intention in order to better understand human action and will. According to Anscombe, intention appears three different ways in the English language. Anscombe's category of intention and a proposed example of each appears in Table 2.

Table 2.

\begin{tabular}{|l|l|}
\hline Intentional Action: & Sexual intercourse \\
\hline Intention for further intention in acting: & $\begin{array}{l}\text { Sexual intercourse with the intention to get } \\
\text { pregnant. }\end{array}$ \\
\hline Expression of intention for the future: & $\begin{array}{l}\text { I will have sexual intercourse with the } \\
\text { intention to get pregnant. }\end{array}$ \\
\hline
\end{tabular}

Defining attributes for the concept of intention and intentional action can be construed from Anscombe's detailed work. For example, the truth of a statement of intention is not a matter of one doing what is intended. In fact, the expression of intention is only a prediction. The road to hell is paved with good intentions is a maxim that further expresses this idea. The intention can be described truthfully, despite the action taken. Anscombe takes the description of truth about intention further, when she explains that intention is purely an interior thing. What is actually done is not considered in the 
question of intention (Anscombe, 1957).

Another defining attribute, interpreted from Anscombe's work, is the presence of practical knowledge:

According to Anscombe (1957): When knowledge or opinion are present concerning what is the case, and what can happen - say $\mathrm{Z}$ - if one does certain things, say $\mathrm{ABC}$, then it is possible to have the intention of doing $\mathrm{Z}$ in doing $\mathrm{ABC}$; and if the case is one of knowledge or if the opinion is correct, then doing or causing $\mathrm{Z}$ is an intentional action, and it is not by observation that one knows one is doing Z; or in so far as one is observing, inferring etc. that $\mathrm{Z}$ is actually taking place, one's knowledge is not the knowledge that a man has of his intentional actions. (p. 50)

When practical knowledge is present, one can give a reason, or answer the question, "why?" for what is voluntary or intentional. One may not be able to give a reason, or answer the question, "why?" for what is unintentional.

Anscombe does not deconstruct unintentional or unintended. The antonyms cannot be conceptually defined by negating the defining attributes of their converses. There is no predicting an unintentional action and if intention is an interior thing, there is no refuting the truth of unintended, even when practical knowledge is present.

At the heart of the philosophical debate about the concept of intention is the semantic content of a sentence versus what it pragmatically conveys. According to King and Stanley (2008), distinction between semantics and pragmatics is fundamental to philosophical theorizing. The semantic value of a word is the standard meaning and does 
not vary from context to context. The pragmatic value is what the speaker conveys and what the recipient construes over and above the semantic content. King and Stanley (2008) explained that most linguists believe semantic values are not relativized to anything. Only pragmatic values are relative to context. Some linguists agree that there is semantic content in a complex expression relative to context. Semantic skepticism is the belief that individual words have semantic content, but there is no semantic content for a sentence or phrase (White, 2011). The semantic modest belief is that a sentence or phrase does have semantic value and that value is important to linguistic understanding (White, 2011).

Intentional language implies a knowledge claim (Anscombe, 1957; King \& Stanley, 2008). Knowledge claims are sensitive to context. The semantic value of knowledge and a speaker's willingness to make knowledge claims varies with context. Even speakers from weak epistemic positions may make knowledge claims dependent on content and context. King and Stanley (2008) use the term felicitous assertion to describe the appropriateness of a speech act. There are two views regarding a speaker's knowledge claim. One view, internalist about reason, is that ethical sentences are not uttered unless there is motivation. The other view, externalist about reason, is that motivation is explained by proper use of an ethical sentence (King \& Stanley, 2008).

Moral blame or moral judgments are features associated with intentional language. Phrases such as "in order to" and "on purpose" are fully intentional (Adams \& Steadman, 2004a). Does moral blame influence judgments of whether something was done intentionally as opposed to judgments of intention influencing moral blame (Leslie, Knobe, \& Cohen, 2006). Relevance Theory (Relevance Theory, n.d.), according to its 
authors, Sperber and Wilson, claims that there is an inferential process that occurs for the recipient of an utterance. Interpretation of an utterance is a result of the combination of explicit content, contextual assumptions, and the speaker's underlying attitude. Is it true that when cause, intention, and outcome are linked, blame or praise can be attributed? Does the question about pregnancy intention postulate moral blame? Is a pregnancy described as unintended to avoid moral blame?

In the social sciences literature, unintended pregnancies are sometimes referred to as unplanned pregnancies. Pragmatically, does the phrase unplanned pregnancy suggest blame? Socially and financially stable couples experience unplanned pregnancies. Society describes blessed events as unplanned, such as financial windfalls and marriage proposals. Even Webster defined unplanned as happening by chance (unplanned, n.d.) inferring fortuitous opportunities or adventure. Unintended is typically reserved for moral challenges such as unintended homicide and suicide, or adverse outcomes such as drug side effects.

Identified are two theories that use the concept of intentional action. The Theory of Planned Behavior (TPB), which began as the Theory of Reasoned Action (Ajzen, 1991) and Social Identity Theory (SIT) (Tajfel, 1974). The key to TPB is behavioral intent. The SIT claims that personal beliefs as well as socially defined roles inform behavior intentions. These theories support the defining attribute, as described by Anscombe (1957), that intentional action can be explained by practical knowledge, real or supposed. No established theory that explains unintended actions, in the presence of knowledge, was found. 


\section{Summary}

The literature was reviewed from a feminist perspective for a better understanding of the social phenomenon of unintended pregnancy. Given this perspective, the issue of unintended pregnancy has been studied in a relatively non-contextual manner. Policy makers support the need to reduce the unintended pregnancy rate $(52 / 1,000)$ in the United States (Unplanned Pregnancy as it Relates to Women, Men, Children, and Society, 2009) knowing that more than half of the women experiencing unintended pregnancies were not using any contraceptive method (Guttmacher Institute, 2013a). The public cost of unintended pregnancy, $\$ 12.6$ billion per year (Sonfield et al., 2011), as well as the many negative consequences associated with unintended pregnancy (Unplanned Pregnancy and Family Turmoil, 2008), have resulted in public health goals to reduce the rate of unintended pregnancy (CDC, 2013).

Publications that dealt with policy, politics, cost, education, contraceptive use or nonuse, contraceptive failure and discontinuation, were divided into two categories: conceptualizing or defining unintended pregnancy and avoiding unintended pregnancy. The literature portrays the phenomenon as a public burden, a financial burden, and a statistical embarrassment. The Literature addressed the many contraceptive and educational means available to avoid unintended pregnancy. It also included a very small amount of qualitative work that identified ambivalence as the one personal characteristic repeatedly association with unintended pregnancy and poor or no contraceptive use.

Despite higher education and access to health care, active duty women experience a $50 \%$ to $100 \%$ higher unintended pregnancy rate $(117 / 1,000)$ than the general population. Focused literature review for this population revealed a history of career and 
reproductive choice inequalities. Unintended pregnancy in this population is largely related to the lack of contraception use (Goyal, Borrero, \& Schwarz, 2011).

Although defining the concept of intention is beyond the scope of this research, defining attributes of the concept found in the literature may contribute to theory development. Intentional language implies a knowledge claim (Anscombe, 1957; King \& Stanley, 2008) and is usually associated with some level of moral blame (Adams \& Steadmean, 2004a). The work of King and Stanley (2008) regarding semantics versus pragmatics revealed how blame may be associated with a question about the intention of a pregnancy.

Finally, the literature was reviewed for established theories that use the concept of intention. The two theories, TPB and SIT, involve intent. These theories agree with Anscombe (1957) that intentional action follows practical knowledge. Unintended action theory has yet to be explored.

The female gender is the categorical center of the phenomenon, unintended pregnancy. Identified as a social problem, the dominantly patriarchal society of the mid twentieth century began the measure and repair of unintended pregnancy. There is a missing truth that has rendered repair ineffective. Unintended pregnancy rates are higher in the United States than any other western nation. American servicewomen experience rates of unintended pregnancy similar to the most oppressed social groups. Only discourse surrounding the experience allows the examination of the specific circumstances, values, and power relations associated with the expressed intention of pregnancy. Feminist research that privileges women's experiences and voices may reveal 
subjugated truths about the phenomenon, address social injustices, and create social transformation. 


\section{Chapter 3}

\section{Methodology}

Unintended pregnancy is a real phenomenon that affects the lives of real women, 3.1 million women in the United States alone, every year. The rate of unintended pregnancy among U.S. military women is $50 \%$ higher than in the nonmilitary population. This study used the lived experience, as described by servicewomen who faced an unintended pregnancy, as a tool for better understanding the social, cultural, political, and historical context in which that pregnancy occurred. The overall purpose of this phenomenological study was to construe and densely describe the lived experience of unintended pregnancy for servicewomen in order to generate skepticism about accepted meanings and interpretations concerning unintended pregnancy and to critique ideologies that distort those meanings and interpretations. The generative question informing this study was: "Why do servicewomen get pregnant when they don't want to be pregnant?" Quantitative research has enriched nursing science with empirical data about unintended pregnancy. Unfortunately, the primary aim of these quantitative studies has been to fix the phenomenon before it has really been explored. This inquiry sought to understand the behavior(s) that led to unintended pregnancy and enrich nursing science with a platform for continued research. The methodology for the inquiry was influenced by various philosophical underpinnings shown in Table 3. A critical hermeneutic approach was implemented for literature review, data collection, and analysis. 
Table 3 .

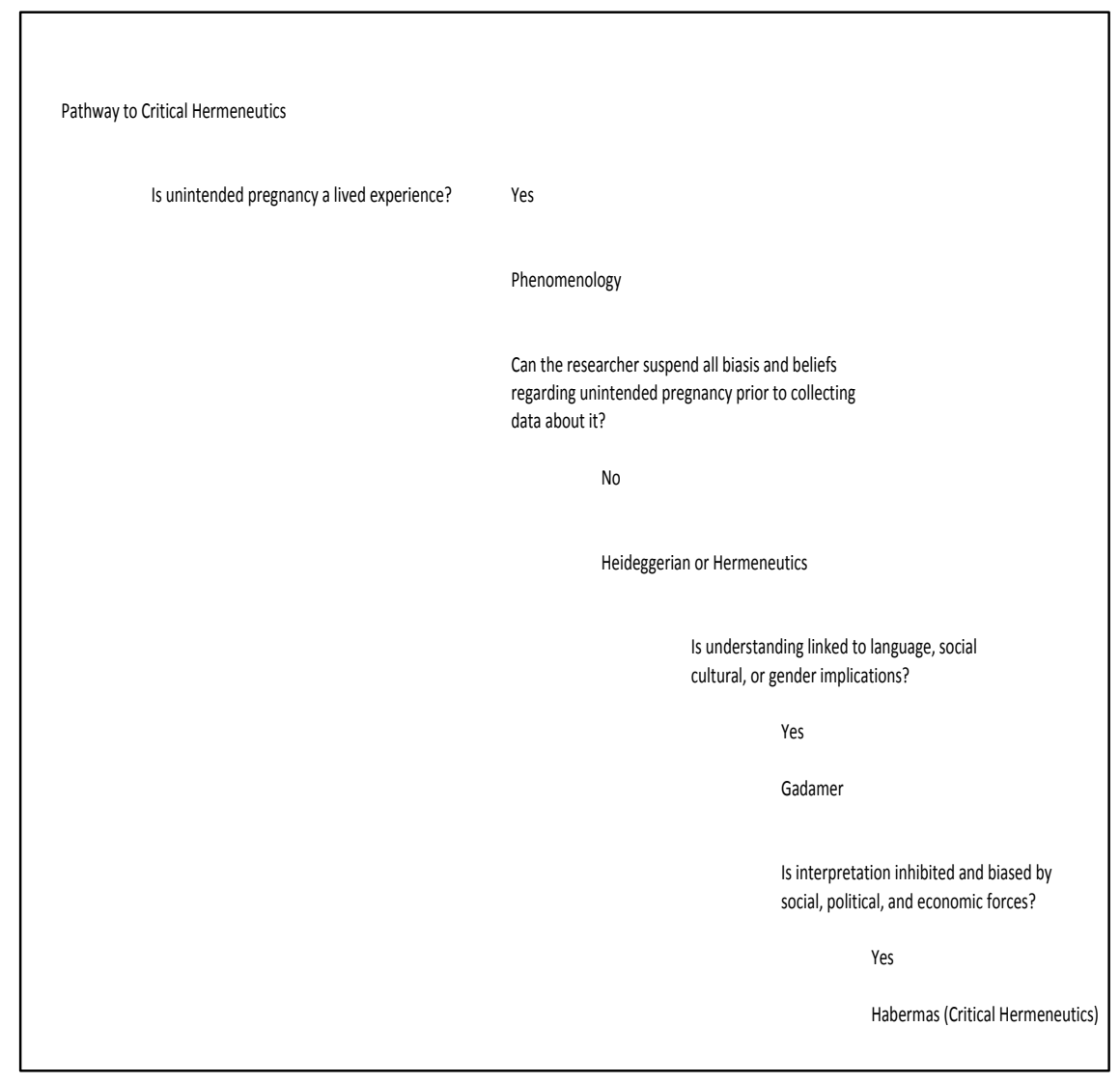

\section{Critical Hermeneutics}

Nursing research is sometimes criticized for claiming a methodology without demonstrating an understanding of the philosophical influences of the approach (Austgard, 2012; Dowling \& Cooney, 2012; Ortiz, 2009). Hermeneutics is often a methodology of choice for midwives (Miles, Francis, Chapman, \& Taylor, 2013). The profession is underpinned by a philosophy that values women and is embedded in their childbearing journey. The reason health professionals are intrigued with phenomenological human science inquiry is that "it may offer plausible insight, and these insights speak not only to our intellectual competence but also to our practical capabilities" (van Manen, 2014, p. 67). Unintended pregnancy is a lived experience. The 
essence of which was yet to be explored. Phenomenology, understood as a philosophy, a tradition, or a method, offered context sensitive research that resulted in language or text capable of changing social or human predicaments.

The methodology of this inquiry moved from a Husserlian to a Heideggerian approach because of at least two concerns. First, the midwife dialogue with the sexually active patient that neither desires a pregnancy nor uses contraception is a reality that could not be bracketed or discounted. Second, there is a postmodern assumption that truth is constructed individually and collectively and that it is multiple and shifting (Macdonald \& Schreiber, 2001). The notion of bracketing, or phenomenological reduction, overriding in Husserlian inquiry (Dowling \& Cooney, 2011), is rejected. The notion that people make sense of their world from the perspective of their realities (both the researcher and the researched), is congruent with a Heideggarian approach or hermeneutics.

Whether the critical properties of the inquiry's methodology were influenced by Gadamer's (2013) views on socio-history and culture or Habermas' (1984) Theory of Communicative Action, it sought to deconstruct, critique, transform, and empower (Merriam, 2009; Schwandt, 2007). The feminist perspective was unavoidable as the inquiry was women centered, contextually female, and attempted to develop new knowledge as a basis for future research into the context in which unintended pregnancy occurs.

There is no single way to conduct a phenomenological study (Dowling, 2012; van Manen, 2014). The inquiry adhered to purposeful sampling with information rich cases (Merriam, 2009), data processing for thematic outcomes (van Manen, 2014), applying the 
hermeneutic cycle, or circle, for reflective writing and interpretation (Kafle, 2011;

Kinsella, 2006), analytic rigor, and a writing style that best represented the participants.

Participants were recruited from the general San Diego area but not excluded for other resident locations as long as face-to-face dialogue could be achieved. Participants were females who experienced an unintended pregnancy while on active duty in one of the Armed Services. Participants were at least 18 years of age.

Participants were recruited through theoretical or purposeful sampling. Participants were chosen for their willingness to share their experience of unintended pregnancy while on active duty. Theoretical sampling is a strategy versus a procedure that is employed to purposefully fill gaps among categories or enhance concepts (Charmaz, 2010).

Recruitment. A recruitment ad (Appendix A) was posted at the Veteran of Foreign War (VFW) and American Legion Posts in the San Diego area. Respondents were asked to share the recruitment information with friends and associates but no referrals were solicited. The 25th Military Women's Luncheon and the Navy Nurse Corps Association of Southern California Luncheon were attended and utilized for personal recruitment.

The recruitment ad led the prospective participant to a website, pregnancymistake.com. The website allowed the prospective participant to provide initial contact and demographic information (Appendix B). If initial demographic information did not meet inclusion criteria for the prospective participant, or if she failed to provide initial consent or documentation that her participation was voluntary, she was excluded from further contact. If she met all inclusion criteria, she was contacted for an in depth 
dialogue regarding her unintended pregnancy experience while she was active duty.

\section{Protection of human subjects}

University of San Diego Institutional Review Board (IRB) approval was obtained prior to proceeding with this inquiry. Initial voluntary consent was confirmed by the completion of the electronic demographic data form (Appendix B). Formal written informed consent for participation in the dialogue was completed by the participant prior to the dialogue (Appendix C). This consent was also available electronically for the participant to review and/or submit. The informed consent explained that the study was voluntary and the participant could discontinue participation at any time.

The participants' rights and interests were considered of primary importance for this inquiry. All personal information, names and other significant identity characteristics of the participants were kept confidential and separated from study data. All electronic data was password protected. All physical data, including audio recordings was safeguarded in a locked file. No one other than the researcher, website management assist, or dissertation committee members had access to this material.

The inquiry posed minimal risk to the participants, as defined by the Office of Human Research Protection (OHRP) under HHS regulations at 45 CFR 46.116(d)(4). There was no risk of physical harm. Posed mental risk was no more than may be encountered in daily life or routine medical or psychological examinations. The topic of this inquiry, unintended pregnancy, is fundamentally personal. Skill and sensitivity regarding discussion of this topic has been mastered through many years of education and clinical practice. Still, questions regarding life disruptions, memories of stigmatized behaviors, and the telling of painful stories can produce emotional stressors and 
necessitate mental health support. The participants' comfort level maintained higher priority than obtaining data. As part of the informed consent, all participants were provided information regarding Veteran Administration mental health services. All participants were offered a summary copy of results.

\section{Data Collection Procedures and Data Analysis}

Face-to-face dialogue was the primary method of data collection for this inquiry. Interactive dialogue is considered the best method of collecting quality data that captures a person's interpretation of an event or experience and allows in-depth exploration (Bloomberg \& Volpe, 2012; Charmaz, 2010). Initial questions were designed to fit the participants' experiences (Appendix D). Initial questions were sufficiently general. The range of questions or focus of the questions changed as dialogue continued. All dialogue was audio recorded. Participants consented to and were visually aware of the audio recording.

Dialogue duration time was intended for one hour and limited to two hours. Interviews took place at a location of convenience for the participant, which by design limited interruption or distraction. The number of interviews completed was ten. Data saturation was reached.

\section{Data Analysis}

In general, the data was examined for patterns within categories, emerging concepts, and themes. A narration was created that represented the participants' intended meanings as expressed in their stories. Richness, depth, and analytic rigor was employed to maintain the quality of hermeneutic research. 


\section{Measures to Assure Credibility}

The methodological validity of this inquiry was assured by the quality and rigor with which data was analyzed in relation to the design (Bloomberg \& Volpe, 2012). Data was gathered from the literature in order to yield a fuller picture of the phenomenon. Assumptions were clarified. Data, including observational data, was collected through interactive dialogue. Analytic findings were reviewed by members of the dissertation committee for confirmation. Through dialogue, observation, and documentation, triangulation was employed to ensure validity (Merriam, 2009).

Phenomenology that is suitable for nursing science necessitates employing a strategy for promoting validity and consistency. The inquiry sought dependability versus reliability, in the sense that reliability refers to the ability to replicate. It was a goal to recognize when inconsistencies occurred. It was also a goal to demonstrate consistent coding. A journaled account or audit trail detailed how the study was conducted and how the data was analyzed. Thick description contextualized the inquiry so that readers may identify with similarities and, consequently, findings may be transferred. The participant sample provided enough diversity that the interpretation of their stories have application to future research. 


\section{Chapter Four}

\section{Findings}

The purpose of this phenomenological study was to generate skepticism about accepted meanings and interpretations concerning unintended pregnancy and to critique ideologies that distort those meanings and interpretations. The generative question was "Why do servicewomen get pregnant when they don't want to be pregnant?" The population subgroup, servicewomen, did not represent high-risk demographic subgroups such as poor and low-income women, women aged 15-17, Black women, and women without a high school diploma. Unintended pregnancy in this subgroup, one and a half times and sometimes twice that of the general population, is its own phenomenon. Each story was an exemplar of society's inadequate activism for girls and general inattention to feminist history.

\section{Participants}

A homogenous purposeful sample was selected in order to understand and describe the experience of unintended pregnancy while active duty. Ten women, represented in Table 4, provided in-depth face-to-face interviews. The ages of the participants at interview ranged from 23 to 65 . The participants experienced an unintended pregnancy when aged 22 through 30. Eight of the participants were White one was Black, and one was Latina. Three were active duty at the interview and the other seven had either separated or retired from military service. The outcome of each unintended pregnancy, termination, birth, adoption and even infant death, was not a qualifier for the study. The sensitivity of each account was evidenced by hushed tones, pauses cloaked in reflective gaze, unanticipated tears, and soulful smiles. These women 
expressed genuine interest in the goals of the study. Each shared a story with detailed intimacy that required little more than attentive listening.

Table 4.

\begin{tabular}{|l|l|l|l|l|l|}
\hline Pseudonym & $\begin{array}{l}\text { Current } \\
\text { age }\end{array}$ & Ethnicity & $\begin{array}{l}\text { Current } \\
\text { military } \\
\text { status }\end{array}$ & $\begin{array}{l}\text { Age at time } \\
\text { of } \\
\text { unintended } \\
\text { pregnancy }\end{array}$ & $\begin{array}{l}\text { Year of } \\
\text { unintended } \\
\text { pregnancy }\end{array}$ \\
\hline Linda & 52 & White & Retired & 27 & 1989 \\
\hline Shannon & 37 & White & Active Duty & 24 & 2002 \\
\hline Heather & 37 & White & Separated & 23 & 2001 \\
\hline Ann & 65 & White & Retired & 22 & 1973 \\
\hline Tashae & 25 & Black & Active Duty & 23 & 2013 \\
\hline Ellen & 62 & White & Retired & 24 & 1977 \\
\hline Brook & 53 & White & Retired & 30 & 1992 \\
\hline Rita & 44 & White & Separated & 22 & 1993 \\
\hline Karen & 48 & White & Retired & 27 & 1994 \\
\hline Arany & 23 & Latina & Active Duty & 22 & 2015 \\
\hline
\end{tabular}

\section{Primary and Secondary Themes}

One primary and two secondary themes emerged from the data. The primary theme was practical knowledge. The secondary themes were sexual daughter and judgment.

Practical knowledge is about being rather than knowing. It is not taught in the classroom but rather learned through experience. Practical knowledge is absorbed from the environment and becomes embodied. Webster defines practical as relating to what is real versus what is possible or imagined and reasonable to do or appropriate for actual use (Practical, n.d. ). Because practice or human behavior reflects not only what one does, but how one thinks (practical knowledge), about what one and others do (Raelin, 2005 , p.83) the implementation of practical knowledge, or practice, is organized around a shared practical understanding (Schatzki, 2001, p. 2). Practical knowledge can be defined 
as the ability to put into effect previously acquired knowledge in specific circumstances (Guzman, 2009). Anscombe (1957) tells us that intentional language implies a knowledge claim and intentional action can be explained by practical knowledge. Without practical knowledge, an action cannot be described as intended. Without practical knowledge true intent to avoid a pregnancy cannot be had.

Is it practical knowledge that contraceptives are used to avoid pregnancy? They should be used consistently and as prescribed. Only two of the ten women interviewed were practicing any form of contraception at the time of their pregnancies. Linda, Rita and Karen felt that they were at low risk for pregnancy because their partners lived far away and sex was infrequent.

Well, my boyfriend at the time went to San Diego State about four hours away. We only saw each other about once a month .... Yeah, I thought it was a low risk. I certainly didn't want to be pregnant. We sometimes used condoms. We obviously didn't that day. (Linda)

I went to Marquette in Milwaukee. Nick went to Madison. We were engaged and the plan was to get married after college. Oops got pregnant. Wasn't on any kind of birth control. (Rita)

I was stationed at Bethesda at the time. My boyfriend was active duty marine corps, just graduated from the Navy Academy. He was out here at Twenty-Nine Palms. I had gone to visit him over the Fourth of July long 
weekend. That is when I got pregnant ...... So it is a little bit different than when you are in the same place. You think, 'I better take my birth control every day' .... As opposed to being distant. (Karen)

Shannon was not in a long distance relationship but described inconsistent contraceptive use.

Initially he would pull out ... we would use condoms but not consistently .... You know it is funny because now I am in a relationship where he doesn't want to get pregnant and he never fails to wear a condom. Every time. No fail. (Shannon)

Is it Practical knowledge that you can get pregnant if you have sex. Many of the participants did not correlate the action of intercourse with getting pregnant.

I never thought beyond that day ... that it could happen ... or the what if it happened. . Never thought much about me ... what could happen to me. (Ann)

I didn't plan. I didn't protect myself. I didn't do anything . ... All this time I thought that I couldn't conceive a child. (Tashae)

I don't know .... It just happened. (Brook) 
I guess I didn't really think about ... that we were really going to get pregnant . ... But I think that he didn't come inside me. Maybe it was naive, but if he didn't come in me, then I wouldn't get pregnant. (Rita)

When asked if she was motivated to avoid a pregnancy, Karen's response verbalized what many of the participants implied.

My motivation was to have sex. It was not related to the motivation to get or not get pregnant. (Karen)

Guzman (2009) described practical knowledge as having a knowledge dimension and a practice dimension. Procedural knowledge about the mechanics of sex and how pregnancy occurs or is avoided may be learned, but embodied knowledge of sexual behavior and practice is developed contextually through subjective interpretation of informal routines, verbage about sex, sexual things, and actions. Guzman (2009) suggested that when procedural knowledge lacks the subjective dimensions of application, performance situations become unstable and outcomes can be uncertain or unplanned.

I knew how you got pregnant. Just didn't think much about it. (Ann)

Maybe I thought if I didn't want it to happen, it wouldn't happen. I really wanted to go on that deployment. I didn't want to be pregnant. He even 
had a child with someone else. Why didn't I think it could happen to me? (Arany)

Many of the participants described home environments that limited talk about sex.

My parents never talked to me about birth control. It was all hush hush. Not that I want to blame my parents for everything, but God Damn it, they were my parents. (Linda)

My parents were not comfortable talking about sex. (Brook)

My mother developed cancer when I was 13 and died when I was 14. I don't remember in that year that she was undergoing treatment and all that, that we had any more conversations. In school, you see the little movie about the rose opening and they separate the girls out, well while I knew the process, I never got around to asking questions. (Ann)

My mom and I did not have that conversation ..... I did not have that female person to talk to other than my girlfriends .... I was going to a Catholic Jesuit school ... you were not supposed to have sex there either. (Rita) 
My mom didn't talk about those things. We were a very Christian family. Christians aren't supposed to have sex. (Ellen)

My mom believed that you don't have sex until you get married; therefore we don't even need to have this discussion. She is very old school. It would have been nice to have had some of those conversations with my mom. I grew up very sheltered and then I got into the military environment. I was shocked. It isn't sheltered. For me it was like something on television. (Karen)

Social structures that foster communication, credibility, respect among its members, and identity sharing will build trust and support practical knowledge sharing (Guzman, 2009). When spontaneous, explorative, and intuitive learning is suppressed, situational understanding may be limited.

I would never have approached the subject with my mother. I think one time when I was little; I was reading Dear Abby .... It said something about masturbation. I said out loud, 'what is masturbation?' There was that awful awkward silence. (Karen)

Sexual Daughters. One of the two subthemes that emerged from the data, sexual daughters, suggests daughters are not recognized as sexual and in-turn, do not identify themselves as sexual. Inadequacies in sexual knowledge, sexual identity, sexual desires, 
and sexual practices inhibit critical thinking about sexual pleasures as well as sexual risks (Fields, 2008). The participants described home environments in which there was either no inference to her sexuality or the supposition that she could be sexual was tainted with criticisms and blame.

I didn't think that I ever equated that, the few minutes (of intercourse), with becoming pregnant. It just never seemed anything to worry about. It was always, don't worry Dad, I am as bad as you think I am. If I get pregnant, then you'll know I was a bad person. Maybe it was fulfilling. So what if I get pregnant, I am just fulfilling the prophecy of what a bad girl I am. It is sad. She (mother) was showing me the lithotomy position that you would be in for a pelvic exam and I remember feeling sick to my stomach just looking at that picture. (Ann)

I was raised as a Jehovah's Witness. You did not have sex. You did not masturbate. Honestly, I was ignorant. It would be shameful to even ask about it. I would be a bad girl to even ask. It would be shameful. You don't even look at condoms. You walk past them in the store and don't look at them on the shelf. No one should see you buying them. (Rita)

My mother pretty much disowned me. Because, guess what, I had sex before I was married. My mom believed that you don't have sex until you get married, therefore, we don't even need to have this discussion. (Karen) 
My dad looked at me like I was a whore or a prostitute if I went out. I was never trusted. I never thought about talking to them, like hey, I think I want to have sex with this person. Can you help me out ... get on birth control? I would have been hit with a sledgehammer. (Linda)

Inadequate knowledge about their own sexuality left the participants vulnerable. Sex happened to them, not without consent, but without mindful participation.

My heart sank. It was also fear. I couldn't remember really having full sex. I think it was more petting .... Or not petting .... I don't remember it being full on entry sex. We never really had that conversation (about sex). (Rita)

In the beginning we weren't really having sex .... When we started fooling around. Perhaps this was another way of me allowing life to make decisions for me ... I didn't have to be an active participant. (Ann)

There were things we forgot to do to avoid pregnancy. (Tashae)

We never had a conversation about what we were actually doing. We never talked about having sex, we just had sex. (Arany) 
Two participants expressed concern about other women experiencing unintended pregnancies today.

I wonder if the guy doesn't just roll over and have sex with her ... no thought ... no planning ... just oh, I want to have sex ... so they do or she does and then, oh dear, another baby. Like it was nothing. (Shannon)

So many are so young and so uneducated. Most of them have no clue about their own anatomy down there. They don't know that they pee out of a different hole than they menstruate out of ... that they have sex out of . . it is very sad. (Heather)

Judgment. The data was saturated with judgment. Although the judgment subtheme may not answer the generative question, "Why do servicewomen get pregnant when they don't want to be pregnant?" It may explain why the pregnancy is described as unintended. The participants expressed judgment from family, they judged themselves, but mostly they expressed professional judgment, real or imagined.

Karen's eyes filled with tears and her expression glazed over as she described her mom's reaction to her pregnancy. Rita shook her head and lowered her gaze as she described her mom's reaction to her pregnancy. 
My mother said, 'Pray for our health' when I am in this desperate state . . .

Their health, my mom and dad's health .... . I am supposed to pray for

them. Yes, that went on for a long time, the disappointment. (Karen)

She was disappointed .... It was still a shamed thing. (Rita)

Several of the participants were very critical of themselves for experiencing an unintended pregnancy. None held their partners accountable. Ellen never shared the fact that she was pregnant with her partner. Heather's response to discovering she was pregnant suggested sole responsibility. Aryan, stoical through most of the interview, unexpectedly burst into tears when asked to describe her feelings when she discovered that she was pregnant.

I think it was our responsibility .... But mostly me. (Linda)

Oh my God, what have I done! (Heather)

He was young ... I was older ... I would have been fraternizing .... We couldn't be dating. (Ellen)

I was shocked, unhappy, and angry with myself. It wasn't his fault. It was mine. That was how I felt. I felt shame. I thought, 'I am just a statistic.' Stupid girl. You had a full-blown scholarship. You blew it. (Rita) 
Oh my God. I am the enlisted girl who gets pregnant ... who can't Control that aspect of her life. (Shannon)

I was so disappointed. Disappointed. I failed. My mom had me when she was 17. She didn't want this for me. (Arany)

Excessive judgment, fear of judgment, or perceived judgment was expressed regarding the participants' military obligations and work environments. All expressed a strong sense of obligation and duty.

I probably worked harder just to convince people that I was responsible and reliable. I felt that I had to prove myself still good enough even though I was pregnant. After he was born, my hours were extended. I think they were testing me to see if I could do it. But I never screwed up. It was hard with day care and everything but I made it work. I had to make it work to keep my position. I didn't want them looking at me like the girl who is trying to get out of something. The sailor who gets knocked up and can't fulfill her duties. I didn't want to lose out on any opportunities. I didn't want people to not respect me. I wasn't just a bimbo blonde enlisted person. I would not have wanted anyone to think that I had planned it. (Shannon) 
I really wanted to go on that deployment. I know that people thought I got pregnant to get out of the deployment. I didn't. I really wanted to go. (Arany)

It is still very much a male dominated work place for pregnant women in the Marine Corps. They will be judged and opportunities will be taken away from them because they are pregnant. No matter what area they work in, they (Marines) are put in administrative positions. Even if they work in a safe area for pregnancy, that they don't need to be moved, they are moved into an administrative position. It irritated me that people feel like they can make comments about your personal life. For a long time, pregnancy had a negative connotation to it. Like this negative thing attached to it. No excitement. It is almost like I expected people to not be happy for me, to say negative things. It is what I expected. Yes. It took a long time to get over that. (Heather)

All the participants were asked how they felt about informing their supervisors, if necessary, of their pregnancies.

Violated. If I kept the baby, I would not have the career as an officer. He (the recruiter) told me; in so many words, I wasn't eligible for the scholarship. So I was put in a corner, of having an abortion and going 
through with my education or losing the scholarship but having the baby. (Linda)

The participants who considered termination of their pregnancies were asked if they considered treatment or referral from a military hospital or clinic.

It is kind of like seeking care for mental health issues. I didn't want the military to know. Somehow, they can hold that (the termination) against you. (Linda)

In the '90s it wasn't discussed. No one would give me options. I was married. It would have been looked at as odd. (Brook)

If we went to a provider at the clinic, maybe they would tell on us. Maybe we would get set back. Maybe I would stay at school longer. Maybe we would get kicked out or something. I was worried that they would think I conceived my child in school or something, you know, I would get the boot and I didn't want to get the boot. People might think I was skating the system . . . that I was just trying to get out of something. You know what I mean? It is not always the circumstance. I just got pregnant. You know what I mean? (Tashae) 
Just running the pregnancy test at the hospital could be a breech of privacy and I'm sure that it is still the case today. (Ann)

Some of the participants recalled judgmental comments verbalized by senior military members.

He said, 'don't be one of those women who have a child right before you have to go to sea. Be a woman who plans ahead.' I was offended actually. He didn't apologize. He just wanted to make his statement. You know like, 'Your child doesn't come in your sea bag.' There are still a lot of things said. (Tasha)

A Division Officer told me that he believed that quite a few people had failed to select (for promotion) because they were single parents. You remember things like that. I asked him, 'really? They look at that when they go to the board?' He said, 'I don't know if they look at it, but they might discuss it. You are not a very good role model.' (Karen)

Several of the participants discussed how they delayed telling anyone about the pregnancy and why.

Well I hid the pregnancy for almost 8 months. I wanted the baby but I didn't want anyone at work to know. 
I didn't tell anyone for a long time ... Oh hello, I'm your new officer and oh yeah, I'm pregnant. Not something that you want to throw on the table. I waited until 20 weeks. Until I started to show. I was in khakis. I always wore the black sweater. They didn't know me very well. It was easy to hide. I stopped wearing my belt with my khakis. I just hoped that I didn't have to take off my sweater. I never took my sweater off. (Heather)

\section{Chapter Summary}

In a one to one interview, ten women, purposefully recruited for this phenomenological research, shared the stories of their unintended pregnancies in the military. Analysis of the data composed from those interviews revealed one primary theme, practical knowledge and two subthemes, sexual daughter and judgment, which may answer, critique, or deconstruct the general question, "Why do service women get pregnant when they don't want to be pregnant?"

In order to provide a shared understanding of the concept of practical knowledge, the philosophical work of Anscombe (1957), Guzman (2009), and Simon (1991), provided a framework for the participants' dialogue supporting practical knowledge as a primary theme. Briefly, where there is no practical knowledge, there can be no intent. Without practical knowledge true intent to avoid pregnancy cannot be had. Dialogue with the participants revealed limited or no practical knowledge regarding pregnancy prevention.

The subtheme, sexual daughters, is supported by Fields' (2008) research. Fields (2008) suggests that inadequacies in sexual knowledge, identity, desires, and practices 
inhibit critical thinking about sexual pleasures and risks. The participants denied conversations with partners about sexual activity, condom use, etc. In general, the participants let sex happen without much planning or awareness. Sex was consensual, but may have lacked mindful participation.

Judgment was a subtheme that was prevalent throughout the data. Judgment was expressed as family judgment, self-judgment, and professional judgment. Although judgment does not answer the generative question regarding why servicewomen get pregnant when they don't want to be pregnant, it implores deconstruction of the accepted meaning of unintended pregnancy. This will be discussed further in Chapter 5. 


\section{Chapter 5}

\section{Discussion}

Unintended pregnancy may likely be an empirical referent for the concept, practical knowledge. This study is suggesting that women may not have the practical knowledge to critically think about their own sexual practices. Defining attributes of this conceptual analysis may include women's poor appreciation of their sexual selves, and fear of judgment for expressing healthy sexual behaviors.

Why do servicewomen get pregnant when they do not want to be pregnant? Why does any woman get pregnant when she does not want to be pregnant? Globally, about four in ten pregnancies are unintended (Singh, Sedgh, \& Hussain, 2010). North America is the only region where overall unintended pregnancy rates have not declined (Singh, Sedgh, \& Hussain, 2010), and the U.S. is estimated to have the highest unintended pregnancy rate of developed countries. Previous research, in the realm of unintended pregnancy, has been primarily empirical, retrospective, and focused on the negative consequences associated with pregnancies that are unintended. Family and pregnancy

planning is affirmed as a social positive. Unintended pregnancy is defined in the literature as a public burden, a globally skewed public health statistic, and a potentially preventable public expense. General consensus is that unintended pregnancy is a bad thing and modern medicine has made it avoidable.

\section{Previous Research}

The rate of all unintended pregnancies among U.S. women aged 15-44 years 2006 to 2010 was 54 per 1,000 pregnancies. Taxpayers spent up to $\$ 12.6$ billion on unintended pregnancy, half of the total public expenditure on birth. The estimated rate, not 
accounting for voluntary pregnancy termination outside of MTFs, of unintended pregnancy in the U.S. military was 117 per 1,000 (Finer \& Zolna, 2011; Lindberg, 2011; Mosher, Jones \& Abma, 2012). Pregnancy- and delivery-related conditions accounted for $57.8 \%$ of all hospitalizations for active duty females in all services, and for some services account for more hospitalizations than any other category of illness or injury for males and females (Defense Medical Surveillance System, 2012). Unintended pregnancy does not belong solely to the poor and low-income, Black women, women without a high school diploma, women aged $20-24$ or sexually active teens, as demonstrated by the participants in this study. In fact, three out of ten women in the U.S. have had an abortion before the age of 45 (Jones, Finer, \& Singh, 2010). Unintended pregnancy belongs to all women.

With more than half of the unintended pregnancies in the U.S. associated with contraceptive nonuse or inconsistent use, contraceptive efficacy, degrees of efficacy, availability, accessibility, costs, failure rates, clinician bias, convenience, user error, and more have been empirically researched. Recommendations and government funded implementations of improved contraceptive accessibility, low or no contraceptive costs, and practitioner education has not decreased the unintended pregnancy rate. Pharmacological research has provided long acting reversible contraceptives, emergency contraceptives, and a variety of user preference delivery methods with excellent efficacy rates. Still, the unintended pregnancy rate has not decreased. Unintended pregnancy among servicewomen and among all women in the U.S. is largely related to no or inconsistent contraceptive use (Goyal, Borrero, \& Schwarz, 2011; Guttmacher Institute, August 2013; Jones, Mosher, Daniel \& Division of Vital Statistics, 2012). 
The WHO reported that improved access to contraception and sex education help prevent unintended pregnancy (Ramos, 2011). Yet, sex education is difficult for Americans. The U.S. has the highest teen pregnancy and birth rates in the developed world as well as significantly higher abortion rates than Western European countries (CDC, 2012). The taboo associated with conversations about sex has interfered with parent and child communication in the home as well as policies for school-based instruction adopted by legislators and school board members. Federal and local debates about sex education are more about perceived social concerns, gender roles, racial hierarchies, conventional morality (Fields, 2008), and less about developing critical thinkers who can recognize themselves and their peers as sexual beings and talk about sex (Kendall, 2013). Educators and politicians argue over whose view of the world sex education should support when the only view that should be considered is that of the student. Freire (1970) explains how positive outcomes cannot be expected from educational programs that do not respect the view of the world held by the people.

We must never merely discourse on the present situation, must never provide the people with programs which have little or nothing to do with their own preoccupations, doubts, hopes, and fears- programs which at times in fact increase the fears of the oppressed consciousness. It is not our role to speak to the people about our own view of the world, nor attempt to impose that view on them, but rather to dialogue with the people about their view and ours. We must realize that their view of the world, manifested variously in their action, reflects their situation in the world. (Freire, 1970, p. 96) 
Attending to their view, her view, of the world. That is where the research should begin.

\section{Credibility}

This study has recognized unintended pregnancy as a female centered phenomenon. Dialogue with servicewomen who lived the experience of unintended pregnancy provided data that extracted the phenomenon from its patriarchal branding as bad and in need of remedy. Simply listening to women challenges the social order that remains in place only through the continuing eclipse of women's experience (Gilligan, 1993. p. xxiv). For this study, unintended pregnancy was no longer a statistic. It was an experience worth exploring. It was an experience predisposed by gender, position, power, and knowledge. The lived experience, as verbalized by these women, was coded into operable themes. The primary theme, practical knowledge, may appear to oversimplify why unintended pregnancy is so prevalent, particularly in this privileged demographic group. But practical knowledge, as well as the subthemes, sexual daughter and judgment, provide philosophical insight into women's failed intention. The exploration of these themes might generate theories for other gender and moral development research. Gilligan (1993) discusses a like concept to practical knowledge.

This psychological seclusion of girls from the public world at the time of adolescence sets the stage for a kind of privatization of women's experience and impedes the development of women's political voice and presence in the public world. The dissociation of girls' voices from girls' experiences in adolescence, so that girls are not saying what they know and eventually not knowing it as well, is 
a prefiguring of many women's sense of having the rug of experience pulled out from under them, or of coming to experience their feelings and thoughts not as real bus as fabrication (Gilligan, 1993. p. xxii)

Recognizing a lack of practical knowledge, unacknowledged sexuality, followed by judgment opens critique and generates skepticism about accepted meanings and interpretations concerning unintended pregnancy. The rest of this chapter will discuss social structures that limit a woman's and a girl's practical knowledge about sex, confound her sexual self, and influence her intentional actions. Deconstructing the phenomenon of unintended pregnancy, by scrutinizing these identified constructs, is the first step to understanding the phenomenon and implementing social change.

\section{Practical Knowledge Deficiency}

Practical knowledge is more than knowing how. It is knowing when, how, what, and what to do. Anscombe (1957) explains that knowledge is irreducibly practical when it is based on actional versus perceptional experience. Practical knowledge must be present for intentional action. For the sexually active, avoiding pregnancy is an intentional action.

Guzman (2009) provided understanding of practical knowledge by focusing on its features. Practical knowledge, as described by Guzman (2009) is situated (in time), is personal, since it involves feelings, intuition, and social identity, and embodied, since a behavior is consciously deployed to perform an action but individuals might be unable to explain why. Practical knowledge is not transferred; it is learned (Revans, 1966). Giddens (1982) suggested learned practical knowledge is dependent on three structures of 
practice. First, structures of significance allow people to communicate with each other. When people understand each other, people use their interpretative schemas built on structures of significance. Second, structures of domination are related to the transformative capability of actions derived from the use of power. Action is connected to that power. Third, structures of legitimation refer to the normative aspects of actions. These structures of practice, part of Giddens' (1982) structuration theory, provide a framework for discussing potential rationale for practical knowledge deficiency among servicewomen.

\section{Structures of significance allow people to communicate with each other.}

History provides long-term perspectives essential to building a long-term future (Bennet, 2006, p. 4). All ten participants in this study were asked if they knew about the history of women and pregnancy in the military. Ann, active duty in the 1970s, recalled an important historical difference.

Certainly, on active duty in 1973, you could not be pregnant. (Ann)

None of the participants had any real knowledge about the history of women in the military and none could discuss the history of pregnancy in the military. According to Freire (1970, p. 109), "People (women) as beings in a situation (the military), find themselves rooted in temporal-spatial conditions which mark them and which they also mark." Historical awareness is educational. When the history of women and pregnancy in the military is investigated, a thematic cycle of subjugation emerges.

Legislation that brought the Women's Army Corps (WAC), the Navy Women's Reserve (WAVES), the Marine Corps Women's Reserve, and the Coast Guard Women Reserve (SPARS) into the military was only for the duration of World War II plus six 
months (Holm, 1992). Legislation drafted in 1946 and passed in 1948 gave women a regular appointment (Women's Armed Services Integration Act of 1948). From the 1940's into the mid 1970's pregnancy and motherhood were considered incompatible with military service. At its founding, the Army Nurse Corps stipulated that nurses, then only female, be unmarried and without dependents (Holm, 1992). Pregnancy, whether married or not, was grounds for discharge during World War II. Executive orders stated that the military could discharge any woman who became the parent, stepparent, or guardian of a child (Women's Armed Services Integration Act of 1948). Male nurses joined the military in 1955. The male nurse's roles as husbands and fathers were never addressed by the federal government (Vuic, 2011). Army regulations regarding marriage for female nurses changed in the 1960s with the needs of the Vietnam War.

Pregnancy continued to be grounds for dismissal prior to the mid 1970s (Morden, 1990). The policy for automatic discharge was challenged and changed but the consequences of pregnancy and it's bearing on military operations remained. In 1966 military women had greater access to abortions than civilians because military hospitals did not have to abide by laws of civilian hospitals (Ponder \& Nothnagle, 2010; Vuic, 2011). Abortion services were quietly provided (Vuic, 2011). There were no formal service policies on abortions prior to 1970 and the availability of abortion services varied by branch of the military, location, physician, and command climate (Burrelli, 2013). In Vietnam, where military medical facilities did not provide abortion services, medical evacuations to countries that did, provided access to abortions for active duty women (Burrelli, 2013; Vuic, 2011). In 1970 the DOD policies regarding abortion were less restrictive than state policies and in 1971, President Nixon directed the military policy 
concerning abortions be made to correspond with the laws of the states where the military bases were located (Burrelli, 2013). In 1975, the DOD ordered that women could no longer be involuntarily discharged for pregnancy or parenthood and in 1976 the Second Circuit Court ruled that discharge because of pregnancy was a violation of Fifth Amendment rights (Holm, 1992).

Elective abortion was made legal in the United States with the Supreme Court case Roe v. Wade (Roe v. Wade, 1973). Individual states were allowed to enact restrictions but not undue burden to women seeking abortion (Harper, Henderson, \& Darney, 2005). Since states had different rules regarding abortion, it was possible for service women to be treated differently depending on the location of the military base. By 1975, military medical personnel were instructed to follow constitutional guidance provided by the Roe decision versus state statutes (Burrelli, 2013). Between 1976 and 1977, the DOD funded more than 26,000 abortions at MTFs or through a beneficiary health plan (Boonstra, 2010).

The recommendation that prohibited the use of DOD funds for abortions was presented as an amendment to the DOD appropriations bill in 1978 (Boonstra, 2010). Exceptions for DOD funding included pregnancy where mother's life is endangered if the fetus is carried to term, and pregnancy resulting from rape or incest that had been reported promptly. DOD funds were prohibited but private funds were used to perform abortions at overseas MTFs (Burrelli, 2013). The rationale for private funding was that safe and reliable civilian facilities were not always available. In 1979, nearly 1,300 privately funded abortions were performed at overseas MTFs (Burrelli, 2013). By the mid 1980s, MTFs overseas performed approximately 30 abortions per year (Boonstra, 2010). 
In 1981 the DOD appropriations act was modified and the rape and incest exceptions to the prohibition of funding were removed. With concerns that the practice of private pay was insensitive to the spirit of the law, the Reagan administration extended the ban on DOD funds to prohibit women from using their own funds in 1988 (Boonstra, 2010). The order remained in effect until 1993 when President Clinton directed the DOD to reverse its policy. The ban on privately paid abortions was lifted until 1995 when congress imposed a statutory ban on the performance of abortions at MTFs, even when paid for with private funds (Boonstra, 2010). The language in the National Defense Authorization Act for FY2013 that, once again, allows government funded abortions for cases of rape and incest was signed into law (Burrelli, 2013). In March of 2013, the Military Access to Reproductive Care and Health (MARCH) for Military Women bill, which would allow MTFs to conduct elective abortions if female service members used private funds to pay for the service (Kime, 2013), was reintroduced. The bill would give military women nearly the same access to reproductive health care as the general population. Unfortunately, the bill was referred to the Subcommittee on Military Personnel and there has been no action. Table 5 summarizes the history of military women and their pregnancies. 


\section{Table 5 .}

Year Historical Event Associated with Current Pregnancy/Abortion Policy in the Military

1948 Women's Armed Services Integration Act of 1948

Army Nurse Corps: Nurses, then only female, must be unmarried and without dependents

1955 Male nurses joined the military but their role as husbands and fathers was never addressed by the federal government

1940s-1970s Pregnancy and motherhood are considered incompatible with military service Automatic discharge for any woman becoming a parent, stepparent, or guardian of a child

Female nurses may marry and remain on active duty

Military women had greater access to abortions than civilian women including medical evacuations from Vietnam to countries that provided access to abortion

DOD* policies regarding abortion are less restrictive than state policies

President Nixon directed the military policy concerning abortions be made to correspond with the laws of the states where the bases were located

Military medical personnel are instructed to follow constitutional guidance versus state statutes regarding abortion

Involuntarily discharge for pregnancy or parenthood is ruled to be a violation of Fifth Amendment rights

DOD funded $>26,000$ abortions at MTFs** and through beneficiary health plans

DOD appropriations bill prohibited use of DOD funds for abortions

Private funds could be used at MTFs overseas

Exceptions included where mother's life is endangered and pregnancy resulting from rape or incest that has been reported promptly

19791,300 privately funded abortions performed at overseas MTFs

1980s MTFs overseas performed 30 abortions per year

1981 Rape and incest exceptions to prohibition of DOD funding for abortions was removed

1988 President Reagan administration extended the ban on DOD funding for abortions and prohibited women from private pay

President Clinton directed the DOD to lift the ban on privately paid abortions at MTFs

1995 Congress banned any performance of abortions at MTFs

Jan 2013 The National Defense Authorization Act for FY2013 allows government funded abortions for cases of rape and incest

March 2013 Military Access to Reproductive Care and Health for Military Women Act or MARCH for Military Women Act - Repeals a statutory restriction on using a medical treatment facility or other facility of the DOD to perform an abortion.

April $2013 \quad$ MARCH bill, S. 777 referred to committee Now has $2 \%$ chance of enactment

*Department of Defense **Military Treatment Facilities 
Being female was so structurally insignificant to the military that she was removed if she participated in behaviors, marriage and parenthood, that alluded to her femaleness. Even legitimate pregnancies were grounds for dismissal until 1976. Has a culture of silence about sex existed for so long that she has no voice? Besides the need to acknowledge healthy sexual behaviors, there are other unmet needs by women in the military, such as freedom from sexual assault, sexual harassment, and sexism. Freire (1970) wrote when people (women) are submerged in reality, they only feel their needs. When there is dialogue that deepens historical awareness, individuals "emerge from reality and perceive the causes of their needs" (Freire, 1970, p. 117).

What is the structure of significance for women in the military? Modernization assimilated the female into the role of soldier, sailor, and marine. She conformed to the role, forfeiting femaleness for acceptance and opportunity. Was she so accommodating that she sacrificed her own view of the world? Does the military adhere to, antidialogical action, "unshakably convinced that it is their mission to 'give' the latter their knowledge and techniques" without considering or respecting her view of the world (Freire, 1970, p. 155). Are servicewomen convinced that they share an intrinsic inferiority? Perceived inferiority may limit the development of critical thinking. Underdeveloped critical thought leads to a deficiency in practical knowledge.

\section{Structures of domination related to the transformative capability of action.}

Education contributes to the development of practical knowledge. Both cognitive knowledge and subjective knowledge demystify the unfamiliar and help women navigate the emerging demands of their sexual futures. Jessica Fields (2008, p. 142) suggested that through sex education, all students have the potential to develop a critical understanding 
and that sex education could "hold transformative, though rarely achieved, potential to promote all students' understanding of girls' and women's entitlement to political, social, economic, and personal pleasure and power."

A service member experiencing an unintended pregnancy in today's military may have been recruited from Texas or Florida, the states that rank number one and two, respectively, for total military recruits (Military Statistics, 2004). There is a high probability that her public school education included Abstinence Only Until Marriage (AOUM) instruction as both Texas and Florida opted for Title $\mathrm{V}$ abstinence only state grant funding in 2010 and 2011 (SIECUS, 2011). Title V funded programs must teach abstinence to the exclusion of other topics which prohibits contraception discussion (SIECUS, 2011). Texas and Florida were among only five states that declined any federal funding for Personal Responsibility Education Program (PREP), an evidenced based comprehensive approach to sexuality education (SIECUS, 2011).

The lifetime risk of a woman dying in a motor vehicle accident in the U.S. is one out of eighty-two (Risk of Death, n.d.). The risk that a young woman will have an abortion, an unwanted pregnancy, before the age of forty-five is one out of three (Guttmacher, July, 2014). Yet, we begin education about seat belts in infancy. That education is reinforced every time she rides in the car. Most girls receive didactic and hands-on education about motor vehicle safety. She witnesses the safe practice of others and the consequences associated with unsafe practices. Her parents stress over the fact that she will one day drive, but prepare her to do so safely.

Belief that female sexuality is a dangerous subject is pervasive in the U.S. (Fields, 2008; Kendall, 2013). Public school sex education curriculum, either AOUM or 
Comprehensive usually focuses on the consequence of sexual behavior and avoids discussion of the behavior itself (Kendall, 2013). The behavior, intercourse, and all that leads to it, is dodged, eluded, evaded, or missing. Concentration is usually on reproduction versus physiological experiences of pleasure. Yet, for most women, sexual activity means much more than potential or actual pregnancy. The participants in this study avoided a conversation with their partners about the sex they shared. And, none of the sex they shared with their partners was for reproductive purposes.

Failing to prepare a young girl for her inevitable sexually active future, and the risks associated with that sexual activity, is a society injustice shared by family and public education. Fields (2013) and Kendall (2013) immersed themselves into today's school based sex education. Both suggested there are ideological and cultural obstacles to safe sex practices. Both agree that subjective knowledge rests on an understanding of one's position in the world. Fields (2013, p. 154) wrote, "Subjective knowledge is crucial to sexual well-being." Allegorically, Fields (2013, p. 154), relates the sex education received in the classroom to driving, "The (education) offers little insight into the obstacles people face behind the wheel and encourage little exploration of the destinations or roadblocks a driver might pursue or encounter." Most of the women in this study report little or no sex education at home.

My mom didn't talk about those things. (Rita)

I would never have approached the subject with my mother. (Karen)

You have to have a family resource ... Someone has to empower you. (Tashae) I don't remember a female that I could have had the conversation with. (Ann) 
Despite the cognitive body of knowledge learned, the constraint on subjective knowledge learned may limit a sense of ability to effect change. Empowering educational situations occur with observation, experience, and conversation. But, when daughters are raised as if they will never experience sex they are deprived of developing an intellectual sexual self.

Structures of legitimation refer to the normative aspects of actions. There are rules of social conduct that provide a moral code of behavior in society and in the military. Many of these rules are unwritten and many are written. The subtheme, judgment, refers to this study's participants' response to structures of legitimation. The dominant culture, through verbalized or non-verbalized consensus determines what is legitimate behavior.

Over time, laws and policies have changed regarding the value and consequences of women's reproduction (Solinger, 2013). There are public policies, Department of Defense policies, societal attitudes, and other variables that determine the legitimacy of pregnancy, intended or unintended. Giddens (1982) explained that when (her) social conduct is inappropriate, (she) risks marginalization. At the annual meeting of the American Sociological Society in 1949, Mirra Komarovsky (1950) read, "But again, the root of the problem is seen in the clash between the biologically determined feminine impulses, on the one hand, and the social roles, on the other, which today, it is alleged, are peculiarly at variance with the biologically set needs of the feminine psyche." Not much has changed. Transformative power exists when she is capable of acting otherwise. Her lack of critical thought and the presence or perceived presence of judgment may render her powerless. 


\section{Implications}

When all women control their own fertility successfully, the number of unintended pregnancies, unintended births, and elective abortions will be reduced to politically and economically insignificant figures. The results of this study may influence the direction of research, education, and public awareness. Investing in social changes that acknowledge female sexual significance, liberate her from sexual ignorance, and legitimize her involvement in sexual activity may empower her with a sense of ability to effect change. Should not every pregnancy be intended?

Practice. In practice and in research it is imperative to understand the problem before trying to repair it. Research and research guided practice has been attempting to resolve the problem, unintended pregnancy, without beginning to understand it. Even the most recent studies (Finer \& Zolna, 2014) acknowledging the increased rate of unintended pregnancy, with large disparities in unintended pregnancies by relationship status, income, and education, still recommend addressing socioeconomic inequities and increasing contraceptive use. If a deficiency in practical knowledge inhibits contraceptive use for $52 \%$ of women, and $62 \%$ of servicewomen, not wanting a pregnancy, interventions that do not address this deficiency may not improve contraceptive use, despite how easy, how effective, or how affordable.

Arguably the most contentious skirmishes in politics involve the issue of abortion, or elective termination of pregnancy. This one topic has such a principled stronghold on political leaders and their constituents, that it directs and sometimes halts the constitutional progression of health care legislation. In the most recent midterm elections, ad campaigns in the state of Tennessee spent more than four million dollars for and 
against a measure regarding abortion services (Boucher, 2015). Over the past few years, Idaho, Kansas, North Dakota, South Dakota and Texas have spent over three million dollars defending anti abortion laws (Culp-Ressler \& Covert, 2014). In the 2014 election cycle, Planned Parenthood's outside spending for and against democratic and republican candidates totaled more than six million dollars. Unimaginable dollars are focused on a symptom, an effect, a consequence of unintended pregnancy. Millions of dollars are spent to maintain and undo abortion legalization. Ironically, as many or more abortions were perfomed in the U.S. in the decades prior to legalization as are today and, outside of selfinduced abortions, without high rates of morbidity and mortality (Solinger, 2013, p. 9). Dollars could be redirected toward public campaigns to empower females by acknowledging sexual behaviors and educating about fertility.

Education. The overall purpose of this phenomenological study was to generate skepticism about the accepted meanings and interpretations concerning unintended pregnancy and to critique ideologies that distort those meanings and interpretations. Education is the vehicle for social change. Recognizing a need to challenge accepted meanings and ideologies is the first step toward freedom from a culture that suppresses practical knowledge about sex. Transforming this social culture must be systematic and deliberate.

Generations of rigid ideals about female sexuality have resulted in an oppressive social structure that perpetuates myths and preserves ignorance. Sexual education for girls is often a defensive response to sexual dangers. Denying sexual behavior for girls or women is safe. Reared in an atmosphere with no dialogue about sex, her ability to think is underdeveloped. Society, through education, can divest itself from these myths. 
Society must invest in permanent dialogue that promotes sexual health. Dialogue, not instruction, about sex should be committed to all stages of female development. Legitimize her sexuality with dialogue about anatomy, body awareness, puberty and adolescent changes, hormonal shifts, crushes, infatuations, arousal, desire, intimacy, love, all or any behaviors leading to orgasm or sexual satisfaction, reproduction, contraception, disease risk, emotional risk, and more. Recognize her sexual significance. Free her from an inability to think, and enable her to effect change. The generation of women that benefit from this paradigm shift will resolve the issue of unintended pregnancy.

Future research. Research should target issues that compromise sexual dialogue for girls. Research should examine interventions that foster learning and knowing. Research should challenge existing social inequalities about sex and promote conversations, interactions, and everyday practices that develop critical thought. Research should investigate female sexual objectivity as well as female sexual subjectivity. Research should appraise awareness and appreciation for sexual dangers as well as sexual pleasures.

Study Limitations

This study contains certain limiting conditions. Like other qualitative designs, analysis rested with the researcher and was limited by researcher subjectivity. Although the Heideggerian approach, or hermeneutics justified researcher influence, the collective truth was still that of both the researcher and the researched. As a midwife, the researcher's previous dialogue with hundreds of women experiencing unintended pregnancies influenced analysis. 
A further limitation of this study was the sensitive nature of the topic. Unintended pregnancy is a very personal experience. Potential participants were approached based on female gender and history of military service. It was a shotgun approach. The hope that someone, with a story to tell, would respond to the solicitation was risky. One woman responded with concern for privacy breeched, "I am appalled that you had access to my military records. That chapter was closed forty years ago."

Aside from bias and sensitivity, the sample was restricted. The study cannot be generalized to other groups. That was not the intended goal. It is anticipated that the knowledge gained from the study could be applied appropriately in other contexts. 
Appendix A

Recruitment Flyer

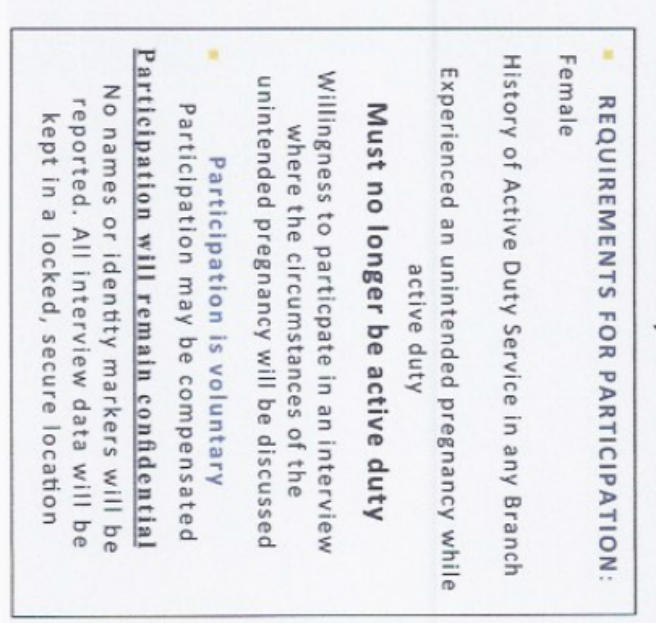

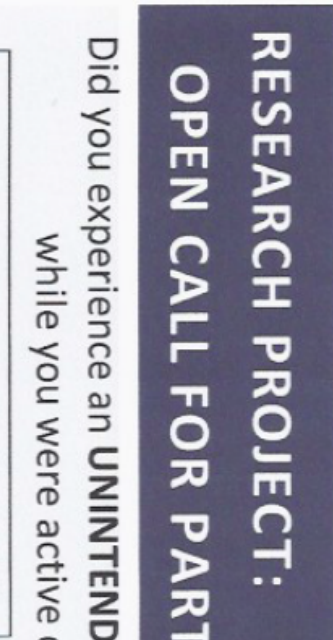

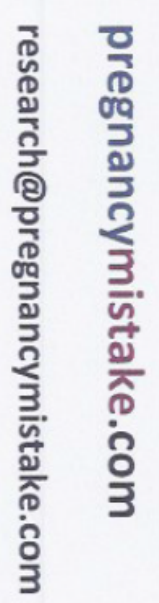

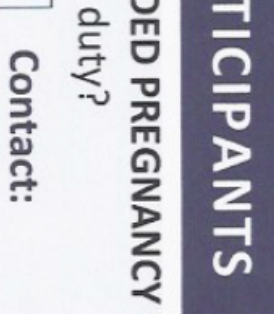
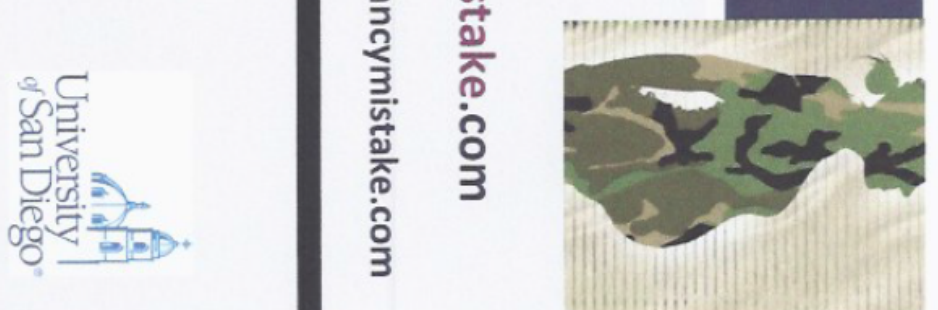


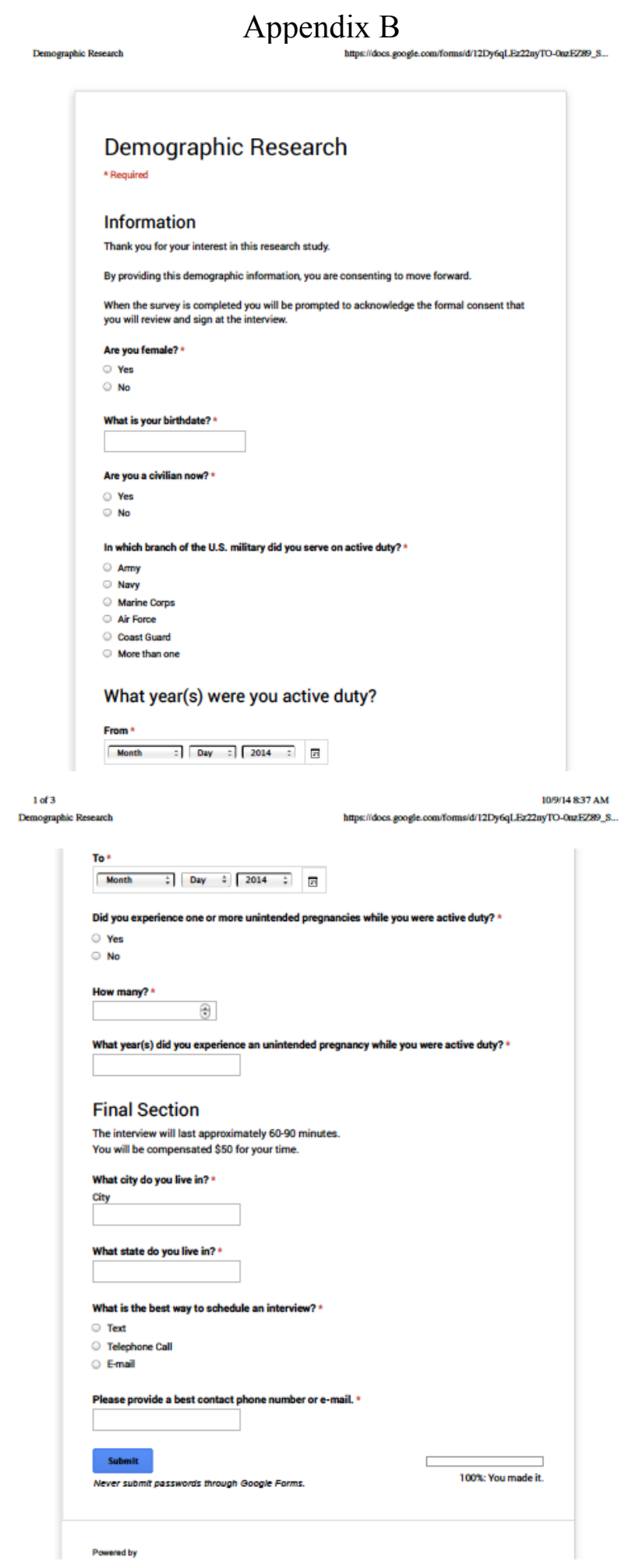

2063 


\title{
Appendix C
}

\author{
University of San Diego \\ Institutional Review Board \\ Research Participant Consent Form \\ For the research study entitled: \\ EXPLORING UNINTENDED PREGNANCY IN THE UNITED STATES MILITARY: \\ A PHENOMENOLOGICAL APPROACH
}

\begin{abstract}
I. Purpose of the research study
Mary K. Phillips is a student in the Hahn School of Nursing at the University of San Diego. You are invited to participate in a research study he/she is conducting. The purpose of this research study is to explore unintended pregnancy in the United States military.
\end{abstract}

\section{What you will be asked to do}

If you decide to be in this study, you will be asked to:

Complete a questionnaire that asks you about your age, ethnicity, branch of the service, years you served and when, in that time, you experienced an unintended pregnancy.

Participate in a private interview about your unintended pregnancy experience while active duty.

You will be audiotaped during the interview.

Your participation in this study will take a total of _ 90 ___ minutes.

\section{Foreseeable risks or discomforts}

Sometimes when people are asked to think about their feelings, they feel sad or anxious. If you would like to talk to someone about your feelings at any time, you can call toll-free, 24 hours a day:

San Diego Mental Health Hotline at 1-800-479-3339 or

Veterans Crisis Line at 1-800-273-8255

\section{Benefits}

While there may be no direct benefit to you from participating in this study, the indirect benefit of participating will be knowing that you helped researchers better understand pregnancy intention or why women may get pregnant when they do not intend to get pregnant.

\section{Confidentiality}

Any information provided and/or identifying records will remain confidential and kept in a locked file and/or password-protected computer file in the researcher's office for a minimum of five years. All data collected from you will be coded with a number or pseudonym (fake name). Your real name will not be used. The results of this research project may be made public and information quoted in 
Appendix C (Continued)

professional journals and meetings, but information from this study will only be reported as a group, and not individually.

VI. Compensation

b) If you participate in the study, the researcher will give you $\$ 50$ in the following way: personally

You will receive this compensation even if you decide not to complete the entire interview.

\section{Voluntary Nature of this Research}

Participation in this study is entirely voluntary. You do not have to do this, and you can refuse to answer any question or quit at any time. Deciding not to participate or not answering any of the questions will have no effect on any benefits you're entitled to, like your health care, or your employment or grades. You can withdraw from this study at any time without penalty.

VIII. Contact Information

If you have any questions about this research, you may contact either:

1) Mary K. Phillips

Email: mkvann@sandiego.edu

Phone: 760-521-4596

2) Jane Georges, PhD, RN

Email: jgeorges@sandiego.edu

Phone:

I have read and understand this form, and consent to the research it describes to me. I have received a copy of this consent form for my records.

Signature of Participant

Date

Name of Participant (Printed)

Date 


\section{Appendix D}

Research Initial Questions

1. How does the participant define unintended pregnancy?

2. Can the participant describe the setting at the time of the pregnancy?

3. To what extent was the participant motivated to avoid pregnancy?

4. To what extent does the participant perceive the father to have been motivated to avoid pregnancy?

5. Can the participant describe her feelings about the pregnancy?

6. What personal/professional/social changes did participants anticipate experiencing or experience as a result of the pregnancy?

7. Can the participant describe any situation where she may have been asked whether or not the pregnancy was intended?

7. What factors does the participant perceive impeded her ability to avoid pregnancy? 


\section{References}

Active Duty. (n.d.). Criminal code of military criminal law applicable to all military members worldwide. Uniform Code of Military Justice. I. General Provisions 801 1. Retrieved from http://www.au.af.mil/au/awc/awcgate/ucmj.htm\#SUB\%20CHAPTER\%201.\%20 GENERAL\%20PROVISIONS

Adams, F., \& Steadman, A. (2004a). Intentional action in ordinary language: Core concept or pragmatic understanding? Analysis, 64, 173-181.

Adams, F., \& Steadman, A. (2004b). Intentional action and moral considerations: Still pragmatic. Analysis 64, 268-276.

Ajzen, I. (1991). The theory of planned behavior. Organizational Behavior and Human Decision Processes, 50, 179-211.

Akers, A. Y., Gold, M. A., Borrero, S., Santucci, A., \& Schwarz, E. B. (2010). Providers' perspectives on challenges to contraceptive counseling in primary care settings. Journal of Women's Health 19, 1163-1170. doi:10.1089/jwh.2009.1735

Ambivalence. (n.d.). In American Heritage Dictionary of the English Language. Retrieved from http:www.thefreedictionary.com/ambivalence.

Anscombe, G. E. M. (1957). Intention. London, England: Basil Blackwell.

Austgard, K. (2012). Doing it the Gadamerian way - using philosophical hermeneutics as a methodological approach in nursing science. Scandinavian Journal of Caring Sciences 26, 829-834. doi: 10.1111/j.1471-6712.2012.00993.x 
Baecher, L., Weaver, M. A., \& Raymond, E. G. (2009). Increased access to emergency contraception: Why it may fail. Human Reproduction, 24, 815-819. doi:10.1093/humrep/den460

Beckett, M. K., Elliott, M. N., Martino, S., Kanouse, D. E., Corona, R., Klein, D. J., \& Schuster, M. A. (2010). Timing of parent and child communication about sexuality relative to children's sexual behaviors. Pediatrics $125,34-42$. doi:10.1542/peds.2009-0806

Bender, S. S. (2008). Three cases of adolescent childbearing decision-making: The importance of ambivalence. Adolescence, 43, 861-879.

Bennet, J. M. (2006). History matters: Patriarchy and the challenge of feminism. Philadelphia, PA: University of Pennsylvania Press.

Biggs, M. A., \& Foster, D. G. (2013). Misunderstanding the risk of conception from unprotected and protected sex. Women's Health Issues 23, e47-e53. doi: 10.1016/j.whi.2012.10.001

Biggs, M. A., Karasek, D., \& Foster, D. G. (2012). Unprotected intercourse among women wanting to avoid pregnancy: Attitudes, behaviors, and beliefs. Women's Health Issues, 22, e311-e318. doi:10.1016/j.whi.2012.03.003

Bloomberg, L. D., \& Volpe, M. (2012). Competing your qualitative dissertation: A road map from beginning to end. Los Angeles, CA: Sage.

Blumer, H. (1969). Symbolic interactionism: Perspective and method. Englewood Cliffs, NJ: Prentice-Hall.

Boonstra, H. D. (2010). Off base: The U.S. military's ban on privately funded abortions. Guttmacher Policy Review, 13(3). Retrieved from 
http://www.guttmacher.org/pubs/gpr/13/3/gpr130302.html Accessed on February $16,2014$.

Boucher, D. (2015, February 2). Millions spent in final days before Tennessee abortion vote. The Tennessean. Retrieved from http://www.tennessean.com/story/news/politics/2015/02/millions

Bray, R. M., Pemberton, M. R., Hourani, L. L., Witt, M., Olmsted, K. L., Brown, J. M., . .. Scheffler, S. (2009). Department of Defense Survey of Health Related Behaviors Among Active Duty Military Personnel (Accession No. ADA527178). Retrieved from http://oai.dtic.mil/oai?verb=getRecord\&metadataPrefix $=$ html\&id Accessed on February 16, 2014.

Burelli, D. F. (2013). Abortion services and military medical facilities. (Congressional Research Service Report for Congress). Retrieved from http://www.law.umaryland.edu/marshall/crsreports/crsdocuments/95387F_01092 013.pdf

Campo, S., Askelson, N., Spies, E. L., \& Losch, M. (2010). Preventing unintended pregnancies and improving contraceptive use among young adult women in a rural, midwestern state: Health promotion implications. Women \& Health, 50, 279-296. doi:1080/03630242.2010.480909

Center on Children and Families at Brookings. (2012). Policy solutions for preventing unplanned pregnancy (CCF Brief No. 47). Washington DC: Adam Thomas.

Centers for Disease Control and Prevention. (2012). Prepregnancy contraceptive use among teens with unintended pregnancies resulting in live births - Pregnancy risk 
assessment monitoring system (PRAMS), 20014-2008. Morbidity and Mortality Weekly Report 61(2), 26-29.

Centers for Disease Control and Prevention. (2013). Ten great public health achievements in the 20th century. Retrieved from http://www.cdc.gov/about/history/tengpha.htm

Charmaz, K. (2010). Constructing grounded theory: A practical guide through qualitative analysis. Los Angeles, CA: Sage

Chesler, E. (1992). Woman of valor: Margaret Sanger and the birth control movement in America. New York, NY: Simon \& Schuster, Inc.

Chung-Park, M. S. (2007). Contraceptive decision-making in military women. Nursing Science Quarterly, 20, 281-287. doi:10.1177/0894318407303432

Commendador, K. A. (2010). Parental influences on adolescent decision making and contraceptive use. Pediatric Nurse, 36, 147-156.

Comstock Act. (n.d.). In Encyclopedia Britannica. Retrieved from http://www.britannica.com/EBchecked/topic/130734/Comstock-Act

Culp-Ressler, T. \& Covert, B. (2014, January 24). These five states have spent more than \$3 million defending anti-abortion laws. Think Progress. Retrieved from http://thinkprogress.org/economy/2014/01/24/3202001/states-abortion

Curtis, S., Evens, E., \& Sambisa, W. (2011). Contraceptive discontinuation and unintended pregnancy: An imperfect relationship. International Perspectives on Sexual and Reproductive Health, 37(2), 58-66. doi:10.1363/3705811

Custer, M., Waller, K., Vernon, S., and O’Rourke, K. (2008). Unintended pregnancy rates among a U.S. military population. Paediatric and Perinatal Epidemiology, 22, 
195-200. doi:10.1111/j.1365-3016.2007.00896.x

Defense Medical Surveillance System. (2012). Hospitalizations among members of the active component, U.S. armed services, 2011. Medical Surveillance Monthly Report 19(4). 10-16.

Dehlendorf, C., Levy, K., Ruskin, R., \& Steinauer, J. (2011). Health care providers' knowledge about contraceptive evidence: A barrier to quality family planning care? Contraception, 81, 292-298. doi:10.1016/j.contraception.2009.11.006

Dennis, A., \& Grossman, D. (2012). Barriers to contraception and interest in over-thecounter access among low-income women: A qualitative study. Perspectives on Sexual and Reproductive Health, 44, 84-91. doi:10.1363/4408412

Department of Defense. (2010). Demographics 2010 profile of the military community. Retrieved from http://www.ncdsv.org/images/DOD_DemographicsProfileOfTheMilitaryCommunit y_2010.pdf

Dowling, M., \& Cooney, A. (2012). Research approaches related to phenomenology: negotiating a complex landscape. Nurse Researcher, 20(2), 21-27.

Dragoman, M., Davis, A., \& Banks, E. (2010). Contraceptive options for women with preexisting medical conditions. Journal of Women's Health, 19, 575-580. doi:10.1089=jwh.2009.1403

Duke, M. R., \& Ames, G. M. (2008). Challenges of contraceptive use and pregnancy 
prevention among women in the U.S. Navy. Qualitative Health Research, 18, 244253. doi:10.1177/1049732307312305

Engelman, P. C. (2011). A history of the birth control movement in America (Healing society: Disease, medicine, and history). Santa Barbara, CA. Praeger.

Fields, J. (2008). Risky lessons: Sex education and social inequality. New Brunswick, NJ: Rutgers University Press.

Finer, L. B. (2010). Unintended pregnancy among U.S. adolescents: Accounting for sexual activity. Journal of Adolescent Health, 42, 312-314. doi: 10.1016/j.jadohealth.2010.02.002

Finer, L. B., \& Kost, K. (2011). Unintended pregnancy rates at the state level. Perspectives on Sexual and Reproductive Health, 43, 78-87. doi:10.1363/4307811

Finer, L. B., \& Zolna, M. R. (2011). Unintended pregnancy in the United States: Incidence and disparities, 2006. Contraception, 84, 478-485. doi: 10.1016/j.contraception_2011.07.013

Finer, L. B., \& Zolna, M. R. (2014). Shifts in intended and unintended pregnancies in the United States, 2001-2008. American Journal of Public Health, 104, S43-S48. doi:10.2105/AJPH.2013.301416

Foster, D. G., Higgins, J. A., Karasek, D., Ma, S., \& Grossman, M. D. (2011). Attitudes toward unprotected intercourse and risk of pregnancy among women seeking abortion. Women's Health Issues, 22, e149-e155. doi:10.1016/j.whi.2011.08.009 Accessed on August 31, 2013. 
Friere, P. (1970). Pedagogy of the oppressed. New York, NY: Continuum International Publishing Group.

Freud, S. (2010). Taboo and the ambivalence of emotions. In Smith, J. K. (Ed.), Totem and taboo: Resemblances between the psychic lives of savages and neurotics (pp. 21-55). Las Vegas, NV: Lits. (Original work published 1913).

Frost, J. J., Finer, L. B., \& Tapales, A. (2008). The impact of publicly funded family planning clinic services on unintended pregnancies and government cost savings. Journal of Health Care for the Poor and Underserved, 19, 778-796. doi:10.1353/hpu.0.0060

Frost, J. J., Lindberg, L. D., \& Finer, L. B. (2012). Young adults' contraceptive knowledge, norms and attitudes: Associations with risk of unintended pregnancy. Perspectives on Sexual and Reproductive Health, 44(2), 107-116. doi: $10.1363 / 4410712$

Gadamer, H. G. (2013) Truth in method. New York, NY: Bloomsbury Academic.

Giddens, A. (1982). Profiles and critiques in social theory. Los Angeles, CA: University of California Press.

Gilligan, C. (1982/1993). In a different voice: Psychological theory and women's development. Cambridge, MA: Harvard University Press.

Glaser, B., \& Strauss, A. (1967). The discovery of grounded theory. Chicago: Aldine.

Glaser, B. (2010). Grounded theory: The study of a concept. Retrieved from http://www.youtube.com/watch?v=OcpxaLQDnLk Accessed on October 2, 2013.

Gold, R. B. (2011). Wise investment: Reducing the steep cost to Medicaid of unintended pregnancy in the United States (Guttmacher Policy Review). Retrieved from 
Guttmacher Institute website:

http://sparky.guttmacher.org/pubs/gpr/14/3/gpr140306.html Accessed on January $9,2014$.

Gossett, D. R., Kiley, J. W., \& Hammond, C. (2013). Contraception is a fundamental primary care service. JAMA, 309, 1997-1998. doi:10.1001/jama.2013.4262

Goyal, V., Borrero, S., Schwarz, E. B. (2011). Unintended pregnancy and contraception among active-duty servicewomen and veterans. American Journal of Obstetrics \& Gynecology, 206, 463-469. doi:10.1016/j.ajog2011.11.018

Grindlay, K., \& Grossman, D. (2013). Contraception access and use among US servicewomen during deployment. Contraception, 87, 162-169.

Grindlay, K., Yanow, S., Jelinska, K., Gomperts, R., \& Grossman, D. (2011). Abortion restrictions in the U.S. military: Voices from women deployed overseas. Women's Health Issues, 21, 259-264. doi:10.1016/j.contraception.2012.09.019

Guilamo-Ramos, V. \& Bouris, A. (2009). Working with parents to promote healthy adolescent sexual development. The Prevention Researcher, 17(4), 7-11.

Guttmacher Institute. (2011). Facts on American teens' sexual and reproductive health. (In Brief: Fact Sheet). Retrieved from http://www.guttmacher.org/pubs/FBATSRH.html Accessed on November 1, 2013.

Guttmacher Institute. (2012a). Facts on American teens' sources of information about sex. (In Brief: Fact Sheet). Retrieved from http://www.guttmacher.org/pubs/FBTeen-Sex-Ed.html Accessed on November 1, 2013. 
Guttmacher Institute. (2012b). Facts on unintended pregnancy in the United States. (In Brief: Fact Sheet). Retrieved from http://www.guttmacher.org/pubs/FBUnintended-Pregnancy-US.html

Guttmacher Institute. (2013a). Contraceptive use in the United States. Retrieved from http://www.guttmacher.org/pubs/fb_contr_use.html

Guttmacher Institute. (2013b). Facts on publicly funded contraceptive services in the United States. (In Brief: Fact Sheet). Retrieved from http://www.guttmacher.org/pubs/fb_contraceptive_serv.html

Guzman, G. (2009). What is practical knowledge? Journal of Knowledge Management, 13(4), 86-98. doi:10.1108/13673270910971851

Habermas, J. (1984). The theory of communicative action volume one: Reason and the rationalization of society. Boston, MA: Beacon Press

Haggar, M. S., \& Chatzisarantis, N. L. D. (2006). Self-identity and the theory of planned behavior: Between- and within-participants analyses. British Journal of Social Psychology, 45, 731-757.

Harding, S. (1995). Strong objectivity: A response to the new objectivity question. Synthese, 104, 331-349.

Harper, C. C., Henderson, J. T., \& Darney, P. D. (2005). Abortion in the United States. Annual Review of Public Health, 26, 501-512. doi:10.1146/annurev.publhealth.26.021304.144351

Henderson, A. (2012). 5 countries that do it better: How sexual prudery makes America a less healthy and happy place. Retrieved from http://www.alternet.org/story/154970/5 countries that do it better $\% 3 \mathrm{~A}$ how sex 
ual prudery makes america a less healthy and happy place. Accessed on February 22, 2014.

Hesse-Biber, S. N. (Editor). (2014). Feminist research practice: A primer (2nd ed.). Thousand Oaks, CA: Sage Publications, Inc.

Higgins, J. A., Hirsch, J. S., \& Trussell, J. (2008). Pleasure, prophylaxis, and procreation: A qualitative analysis of intermittent contraceptive use and unintended pregnancy. Perspectives on Sexual and Reproductive Health, 40, 130-137.

Hoffman, S. (2006). By the numbers: The public costs of teen childbearing. The National Campaign to Prevent Teen Pregnancy. Retrieved from http://thenationalcampaign.org/resource/numbers

Hoggart, L. (2012). 'I'm pregnant ... what am I going to do?' An examination of value judgments and moral frameworks in teenage pregnancy decision making. Health, Risk \& Society, 14, 533-549. doi:10.1080/13698575.2012.706263

Holloway, I. \& Wheeler, S. (2010). Qualitative research in nursing and healthcare, 3rd edition. Oxford, United Kingdom: John Wiley \& Sons.

Holm, J. (1992). Women in the military: An unfinished revolution (Rev. ed.). Novato, CA: Presidio Press

Holt, K., Grindlay, K., Taskier, M., \& Grossman, D. (2011). Unintended pregnancy and contraceptive use among women in the U.S. military: A systematic literature review. Military Medicine, 176(9), 1056-1064.

Huynh, L., McCoy, M., Law, A., Tran, K. N., Knuth, S., Lefebvre, P., . . Duh, M. S. (2013). Systematic literature review of the costs of pregnancy in the US. 
PharmacoEconomics, 31, 1005-1030. doi:10.1007/s40273-013-0096-8

James, E. A., \& Rashid, M. (2013). "Welfare queens" and "teen moms": How the social construction of fertile women impacts unintended pregnancy prevention policy in the United States. Policy, Politics, \& Nursing Practice Retrieved from http://ppn.sagepub.com/content/early/2013/12/26/1527154413510408. doi:10.1177/1527154413510408

Jones, J., Mosher, W., Daniels, K. (2012, October 18). Current contraceptive use in the United States, 2006-2010, and changes in patterns of use since 1995. National Health Statistics Reports 60. 1-26.

Jones, R. K. \& Dreweke, J. (2011). Countering conventional wisdom: New evidence on religion and contraceptive use. Retrieved from http://www.guttmacher.org/pubs/Religion-and-Contraceptive-Use.pdf

Jones, R. K, Finer, L. B., \& Singh, S. (2010) Characteristics of U.S. abortion patients, 2008. New York, NY: Guttmacher Institute.

Jones, R. K., \& Kavanaugh, M. L. (2011). Changes in abortion rates between 2000 and 2008 and lifetime incidence of abortion. Obstetrics \& Gynecology, 117, 13581366. doi:10.1097/AOG.0b013e31821c405e

Kafle, N. P. (2011). Hermeneutic phenomenological research method simplified. Bodhi: An Interdisciplinary Journal, 5, 181-200.

Kaufmann, R. B., Morris, L., \& Spitz, A. M. (1997). Comparison of two question sequence for assessing pregnancy intention. American Journal of Epidemiology, 
$145,810-816$.

Kaye, K., Suellentrop, K., \& Sloup, C. (2009). The fog zone: How misperceptions, magical thinking, and ambivalence put young adults at risk for unplanned pregnancy. Retrieved from Washington DC: National Campaign to Prevent Teen and Unplanned Pregnancy. Retrieved from http://www.thenationalcampaign.org/fogzone/PDF/FogZone.pdf

Kendall, N. (2013). The sex education debates. Chicago, IL: The University of Chicago Press.

Kime, P. (2013). Bill would allow self-paid abortion in MTFs. Outside the Wire. Retrieved from http://www.armytimes.com/article/20130326/BENEFITS06/303260 Accessed on May 2, 2013.

King, J. C., \& Stanley, J. (2008). Semantics, pragmatics, and the role of semantic content. In Zoltan Gendler Szabo (Ed.), Semantics versus pragmatics (pp. 111-161). Oxford, England: Oxford University Press.

Kinsella, E. A. (2006). Hermeneutics and critical hermeneutics: Exploring possibilities within the art of interpretation. Forum Qualitative Sozialforschung / Forum: Qualitative Social Research, 7(3), Art. 19. Retrieved from http://nbnresolving.de/um:nbn:de:0114-fqs0603190

Klein, D. A., \& Adelman, W. P. (2008). Adolescent pregnancy in the U.S. military: What we know and what we need to know. Military Medicine, 173, 658-665. 
Knobe, J. (2004). Intention, intentional action and moral considerations. Analysis, 64, $181-187$.

Knobe, J. (2006). The concept of intentional action: A case study in the uses of folk psychology. Philosophical Studies, 130, 203-231. doi:10.007/s11098-004-4510-0

Komarovsky, M. (1950). Functional analysis of sex roles. American Sociological Review, 15, 508-516. Retrieved from http://www.jstor.org/stable/2087310

Leslie, A. M., Knobe, J., \& Cohen, A. (2006). Acting intentionally and the side-effect effect: Theory of mind and moral judgment. Psychological Science, 17, 421-427.

Lindberg, L. D. (2011). Unintended pregnancy among women in the U.S. military. Contraception, 84, 249-251. doi: 10.1016/j.contraception.2011.01.017

Lindberg, L. D., \& Maddow-Zimet, I. (2012). Consequences of sex education on teen and young adult sexual behaviors and outcomes. Journal of Adolescent Health, 51, 332-338. doi:10.1016/j.jadolhealth.2011.12.028

Lindberg, L. D., \& Singh, S. (2008). Sexual behavior of single adult American women. Perspectives on Sexual and Reproductive Health, 40, 27-33. doi: $10.1363 / 4002708$

Longino, H. E. (1993). Feminist standpoint theory and the problems of knowledge. Signs: Journal of Women in Culture and Society, 19, 201-212.

MacDonald, M., \& Schreiber, R. S. (2001). Constructing and deconstructing grounded theory in a postmodern world. In R. S. Schreiber \& P.N. Stern (Eds.), Using grounded theory in nursing. New York, NY: Springer Publishing Company. 
Maxson, P., \& Miranda, M. L. (2011). Pregnancy intention, demographic differences, and psychosocial health. Journal of Women's Health, 20, 1215-1223. doi:10.1089/jwh.2010.2379

Medicine and Public Health, 1890-1930. (n.d.). In Encyclopedia of American History: The emergence of modern America, 1900-1928, revised edition (volume VII). Retrieved from http://www.fofweb.com/History/MainPrintPage.asp?iPin+EAHVII

Merriam, S. B. (2009). Qualitative research: A guide to design and implementation. San Francisco, CA: John Wiley \& Sons.

Miles, M., Francis, K., Chapman, Y., \& Taylor, B. (2013). Hermeneutic phenomenology: A methodology of choice for midwives. International Journal of Nursing Practice, 19, 409-414. doi:10.1111/ijn.12082

Miller, K. S., Fasula, A. M., Dittus, R. E., Wiegand, R. E., Wyckoff, S. C., \& McNair, L. (2009). Barriers and facilitators to maternal communication with preadolescents about age-relevant sexual topics. AIDS and Behavior, 13, 365-374. doi:10.1007/s10461-007-9324-6

Monea, E. \& Thomas, A. (2011). Unintended pregnancy and taxpayer spending. Perspectives on Sexual and Reproductive Health 43, 88-93. doi:10.1363/4308811 Morden, B. J. (1990). The women's army corps 1945-1978. Washington, DC: U.S. Government Printing Office.

Mosher, W. D., Jones, J., \& Abma, J. C. (2012). Intended and unintended births in the United States: 1982-2010. National health statistics reports; no 55. Retrieved from www.ncbi.nlm.nih.gov/pubmed/23115878 Accessed on January 8, 2014. 
Musick, K., England, P., Edgington, S., \& Kangas, N. (2009). Education differences in intended and unintended fertility. Social Forces, 88, 543-572. doi:10.1353/sof.0.0278

Navy and Marine Corps Public Health Center. (2012). Sexual Health and Responsibility Program (SHARP). Retrieved from http://www.nmcphc.med.navy.mil/Healthy_Living/Sexual_Health/sharp_main.as $\mathrm{px}$

Nettleman, M. D., Chung, H., Brewer, J., Ayoola, A., \& Reed, P. L. (2007). Reasons for unprotected intercourse: Analyisis of the PRAMS survey. Contraception, 75, 361366. doi: 10.1016/j.contraception.2007.01.011

Office of the Under Secretary of Defense (Comptroller) / Chief Financial Officer.Overview. (2012). Overview: United States Department of Defense Fiscal Year 2013 Budget Request. Retrieved from http://comptroller.defense.gov/defbudget/fy2013/Fy2013_Budget_Request_Overv iew_Book.pdf

Ortiz, M. R. (2009). Hermeneutics and nursing research: History, processes, and exemplar. Southern Online Journal of Nursing Research, 9. Retrieved from http://0-web.a.ebscohost.com.sally.sandiego.edu/ehost/delivery?sid=

Pazol, K., Zane, S. B., Parker, W. Y., Hall, L. R., Berg, C., \& Cook, D. A. (2011). Abortion Surveillance - United States, 2008. Morbidity and Mortality Weekly Report, 60(SS-15) 1-41.

Pizarro, D. A., Uhlmann, E., \& Bloom, P. (2003). Causal deviance and the attribution of moral responsibility. Journal of Experimental Social Psychology 39, 653-660. 
Ponder, K. L., \& Nothnagle, M. (2010). Damage control: Unintended pregnancy in the United States military. Journal of Law, Medicine, and Ethics, 386-395. doi:10.1111/j.1748-720X.2010.00497.x

Practical. (n.d.) In Merriam-Webster's online dictionary. Retrieved from http://www.merriam-webster.com/dictionary/practical

Raelin, J. (2005). The role of facilitation in praxis. Organizational Dynamics, 35, 83-95. doi: 6/j.orgdyn.2005.12.008

Raine. T. R., Gard, J. C., Boyer, C. B., Haider, S., Brown, B. A., Hernandez, F. A. R., \& Harper, C. C. (2010). Contraceptive decision-making in sexual relationships: Young men's experiences, attitudes, and values. Cult Health Sex, 12, 373-386. doi:10.1080/13691050903524769

Ramos, S. (2011) Interventions for preventing unintended pregnancies among adolescents: RHL commentary. The WHO Reproductive Library; Geneva: World Health Organization. Retrieved from http://apps.who.int./rhl/adolescent/cd005215_ramoss_com/en/ Accessed on April 11, 2014.

Revans, R. W. (1966). The theory of practice in management. London: Macdonald. Risk of Death, (n.d.). In Bandolier, evidence based rethinking about health care. Retrieved from http://www.medicine.ox.ac.uk/bandolier/booth/Risk/trasnsportpop.html Roe v. Wade, 410 U.S. 113 (1973). 
Sales, J. M., Spitalnick, J., Milhausen, R. R., Wingood, G. M., DiClemente, R. J., Salazar, L. F., \& Crosby, R. A. (2009). Validation of the worry about sexual outcomes scale for use in STI/HIV prevention interventions for adolescent females. Health Education Research, 24(1), 140-152.

Santelli, J., Ott, M. A., Lyon, M., Rogers, J., \& Summers, D. (2006). Abstinence -only education policies and programs: A position paper of the Society for Adolescent Medicine. Journal of Adolescent Health, 38, 83-87.

doi:10.1016/j.jadohealth.2005.06.002

Santelli, J., Rochat, R., Hatfield-Timajchy, K., Gilbert, C., Curtis, K., Cabral, R., . . . Schieve, L. (2003). The measurement and meaning of unintended pregnancy. Perspectives on Sexual and Reproductive Health, 35, 94-101.

Schatzki, T. (2005). Introduction: practice theory. In T. Schatzki, K. Knorr Ceytina, \& E. Savigny (Eds.), The Practice Turn in Contemporary Theory (p. 2). London: Routledge.

Scott, J. (1991). the evidence of experience. Critical Inquiry, 17, 773-797.

Shields, W. (2009). A fast track solution for reducing unintended pregnancies in the US: Increase federal support for life-long provider education and training in reproductive health. Contraception 80, 231-233. doi:10.1016/j.contraception.2009.06.001 
Singh, S., Sedgh, G., \& Hussain, R. (2010). Unintended pregnancy: worldwide levels, trends and outcomes. Studies in Family Planning, 41, 241-250. doi: $10.1111 /$ j.1728-4465.2010.00250.x

Solinger, R. (2013). Reproductive politics: What everone needs to know. New York, NY: Oxford University Press.

Sonfield, A. (2012). Sex education remains active battleground. Contraceptive Technology Update 33, 34.

Sonfield, A., \& Gold, R. B. (2012). Public funding for family planning, sterilization and abortion services, FY 1980-2010. Retrieved from Guttmacher Institute website: http://www.guttmacher.org/pubs/Public-Funding-FP-2010.pdf>

Sonfield, A., \& Kost, K. (2013). Public costs from unintended pregnancies and the role of public insurance programs in paying for pregnancy and infant care: Estimates for 2008. Retrieved from http://www.guttmacher.org/pubs/public-costs-ofUP.pdf

Sonfield, A., Kost, K., Gold, R. B., \& Finer, L. B. (2011). The public costs of births resulting from unintended pregnancies: National and state-level estimates. Perspectives on Sexual and Reproductive Health, 43, 94-101. doi: $10.1363 / 4309411$

Strauss, S. (1987). Qualitative analysis for social scientists. Cambridge, UK: Cambridge University Press.

Speidel, J. J. \& Harper, C. C. (2008). The potential of long-acting reversible contraception to decrease unintended pregnancy. Contraception, 78, 197-200. doi:10.1016/j.contraception.2008.06.001 
Strauss, S., \& Corbin, J. (1998). Basics of qualitative research: Techniques and procedures for developing grounded theory, 2nd ed. Thousand Oaks, CA: Sage.

Stanger-Hall, K. F., \& Hall, D. W. (2011). Abstinence-only education and teen pregnancy rates: Why we need comprehensive sex education in the U.S. Plos One, 6(10), 111. doi:10.1371/journal.pone. 0024658

Tajfel, H. (1974). Social identity and intergroup behavior. Soc. Sci. Inf. 13, 65-93

Taylor, D. (2011). Evidence to inform policy, practice and education for unintended pregnancy prevention and management. JOGNN, 40, 773-774. doi:10.1111/j.15526909.2011.01295.x

Taylor, D., \& James, E. A. (2011). An evidence-based guideline for unintended pregnancy prevention. Journal of Obstetric, Gynecologic, and Neonatal Nursing, 40, 782-793. doi:10.1111/j.1552-6909-.2011.01296

Trenholm, C., Devaney, B., Fortson, K., Quay, L., Wheeler, J., \& Clark, M. (2007). Impacts of fourt Title V, section 510 abstinence education programs: Final report. Retrieved from U.S. Department of Health and Human Services Office of the Assistant Secretary for Planning and Evaluation. (Contract No.: HHS 100-98-0010, MPR Reference No.: 8549-110). Retrieved from http://www.mathematicampr.com/publications/PDFs/impactabstinence.pdf

Trussell, J., Schwarz, E. B., \& Guthrie, K. (2010). Research priorities for preventing unintended pregnancy: Moving beyond emergency contraception pills. Perspectives on Sexual and Reproductive Health 42, 8-9. doi:10.1363/420810 
Tsui, A. O., McDonald-Mosley, R., \& Burke, A. E. (2010). Family planning and the burden of unintneded pregnancies. Epidemiological Review 32, 152-174. doi:10.1093/epirev/mxq012

United States Department of Defense. (2010). Demographics 2010 profile of the military community. Retrieved from http://www.icfi.com/markets/defense/campaigns/workforce-research Accessed on April 28, 2013.

United States Department of Defense. (2013). Operation and maintenance overview fiscal year 2013 budget estimates. Retrieved from http://comptroller.defense.gov/defbudget/fy2013/fy2013_OM_Overview.pdf

United States Department of Health and Human Services Office of Population Affairs. (2010). Reproductive health and healthy people 2020. Retrieved from http://healthypeople.gov/2020/topicsobjectives2020/overview.aspx?topicid=13 Unplanned Pregnancy and Family Turmoil. (2008). In The national campaign to prevent teen and unplanned pregnancy (Science Says, Number 34). Retrieved from http://thenationalcampaign.org/resource/science-says-34

Unplanned Pregnancy as it Relates to Women, Men, Children, and Society. (2009). In The national campaign to prevent teen and unplanned pregnancy (Science Says Number 40). Retrieved from http://thenationalcampaign.org Accessed on November 1, 2013.

van Manen, M. (2014). Phenomenology of practice. Walnut Creek, California: Left Coast Press Inc. 
Vuic, K. D. (2011). Officer, nurse, woman: The army nurse corps in the Vietnam War. Baltimore, Maryland: The Johns Hopkins University Press.

Whelpton, P. K., \& Kiser, C. V. (1943). Social and psychological factors affecting fertility: I. Differential fertility among 41,498 native-white couples in Indianapolis. The Milbank Memorial Fund Quarterly, July 21(3), 221-280.

White, H. D. (2011). Relevance theory and citations. Journal of Pragmatics, 43, 33453361. doi:10.1016/j.pragma.2011.07.005

Wilson, E. K., Dalberth, B. T., Koo, H. P., \& Gard, J. C. (2010). Parents' perspectives on talking to preteenage children about sex. Perspectives on Sexual and Reproductive Health, 42, 56-63. doi:10.1363/4205610

Wilson, E. K. \& Koo, H. P. (2010). Mothers, fathers, sons, and daughters: Gender differences in factors associated with parent-child communication about sexual topics. Reproductive Health 7(31), 1-9. doi:10.1186/1742-4755-7-31

Women's Armed Services Integration Act of 1948, Pub. L. No. 625-80th Congress, Chapter 449-2d Session. S. 1641 (1948).

World Health Organization. (2012). From evidence to policy: Expanding access to family planning. Strategies to increase use of long acting and permanent contraception (Policy Brief). Retrieved from http://apps.who.int/iris/bitstream/10665/75161/1/WHO_RHR_HRP_12.20_eng.pd 
